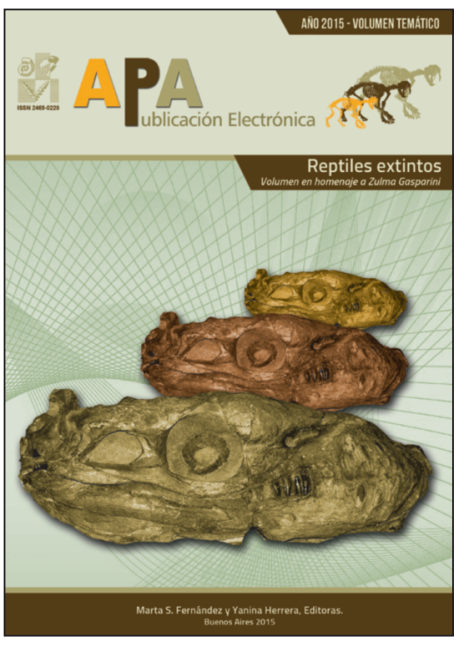

\title{
ESTADO DEL CONOCIMIENTO DE LAS TORTUGAS EXTINTAS DEL TERRITORIO ARGENTINO: UNA PERSPECTIVA HISTÓRICA
}

MARCELO S. DE LA FUENTE1

JULIANA STERLI²

${ }^{1}$ IANIGLA-CONICET. Museo de Historia Natural de San Rafael. Parque Mariano Moreno S/Nº, Avenida Balloffet S/Nº, M5602DPH San Rafael, Mendoza, Argentina. ${ }^{2}$ CONICET. Museo Paleontológico Egidio Feruglio de Trelew. Av. Fontana 140, U9100GYO Trelew, Chubut, Argentina.

Recibido: 17 de Agosto de 2015 - Aceptado: 28 de Septiembre de 2015

Para citar este artículo: Marcelo S. de la Fuente y Juliana Sterli (2015). Estado del conocimiento de las tortugas extintas del territorio argentino: una perspectiva histórica. En: M. Fernández y Y. Herrera (Eds.) Reptiles Extintos - Volumen en Homenaje a Zulma Gasparini. Publicación Electrónica de la Asociación Paleontólogica Argentina 15(1): 1-19.

Link a este artículo: http://dx.doi.org/10.5710/PEAPA.28.09.2015.95

DESPLAZARSE HACIA ABAJO PARA ACCEDER AL ARTÍ́CULO

Asociación Paleontológica Argentina Maipú $6451^{\circ}$ piso, C1006ACG, Buenos Aires República Argentina

Tel/Fax (54-11) 4326-7563 Web: www.apaleontologica.org.ar

Otros artículos en Publicación Electrónica de la APA 15(1):

\section{Fernández \& Campos}

OPHTHALMOSAURIDS

(ICHTHYOSAURIA: THUNNOSAURIA):

ALPHA TAXONOMY, CLADES AND

NAMES.

\section{Paulina Carabajal}

GUIA PARA EL ESTUDIO DE LA NEUROANATOMÍA DE DINOSAURIOS SAURISCHIA, CON ENFASIS EN FORMAS SUDAMERICANAS.

\section{Pol \& Leardi}

DIVERSITY PATTERNS OF NOTOSUCHIA (CROCODYLIFORMES, MESOEUCROCODYLIA) DURING THE CRETACEOUS OF GONDWANA. 


\title{
ESTADO DEL CONOCIMIENTO DE LAS TORTUGAS EXTINTAS DEL TERRITORIO ARGENTINO: UNA PERSPECTIVA HISTÓRICA
}

\author{
MARCELO S. DE LA FUENTE${ }^{1}$ Y JULIANA STERLI²
}

'IANIGLA-CONICET. Museo de Historia Natural de San Rafael. Parque Mariano Moreno S/N, Avenida Balloffet S/Nº, M5602DPH San Rafael, Mendoza, Argentina. mdelafuente@mendoza-conicet.gov.ar; mdelafuente1910@gmail.com

2CONICET. Museo Paleontológico Egidio Feruglio de Trelew. Av. Fontana 140, U9100GYO Trelew, Chubut, Argentina. jsterli@mef.org.ar

\begin{abstract}
Resumen. El estudio de las tortugas extintas en el territorio argentino se inició hace 157 años cuando el naturalista francés Auguste Bravard nominó la primera especie de tortuga. Desde ese entonces hasta la actualidad se incrementó el conocimiento de los Testudinata del territorio argentino en una progresión geométrica, desde las meras nominaciones de especies sin ningún tipo de caracterización, realizadas por los naturalistas y los pioneros de los estudios paleontológicos del siglo XIX, hasta los estudios anatómicos detallados de la actualidad. Arbitrariamente hemos reconocido tres etapas diferentes en el desarrollo de estos estudios. Una etapa inicial que se extendió por más de 100 años y que abarcó entre 1858 y 1965 caracterizada por menciones esporádicas sobre nuevas especies de tortugas fósiles realizadas por naturalistas extranjeros y argentinos, así como por pioneros de la paleontología. Una segunda etapa que abarcó 27 años comprendida entre los años 1966 y 1993 en la que se realizaron mayormente trabajos de síntesis por parte de paleontólogos de vertebrados y paleoherpetólogos argentinos incluyendo, en algunos casos, la participación de especialistas extranjeros. La última etapa, comprendida entre los años 1994 y 2015, está caracterizada por el estudio sistemático de las tortugas extintas con aportes significativos sobre la anatomía, taxonomía y biogeografía de los Testudinata mesocenozoicos del territorio argentino.
\end{abstract}

Palabras clave. Testudinata. Triásico. Jurásico. Cretácico. Paleógeno. Neógeno. Cuaternario. Argentina.

Abstract. STATE OF KNOWLEDGE OF THE EXTINCT TURTLES OF THE ARGENTINE TERRITORY: A HISTORICAL PERSPECTIVE. The study of extinct turtles in the Argentine territory began 157 years ago when the French naturalist Auguste Bravard nominated the first species of turtle. Since then, the knowledge of the Testudinata in the Argentine territory increased in a geometric progression from mere nominations of species without any characterization, made by naturalists and pioneers of the paleontological studies of the nineteenth century, to the recent detailed anatomical studies. Three different stages in the history of the study of turtles in Argentina can be recognized. The initial stage, that lasted more than 100 years, between 1858 and 1965, the studies were carried out by foreign and Argentine naturalists as well as by pioneers of paleontology. The second stage that lasted 27 years, between 1966 and 1993 in which synthesis works have mainly done by vertebrate paleontologists and Argentine paleoherpetologists, in some cases with the participation of foreign experts. The last stage, between 1993 and 2015, is characterized by significant contributions on the anatomy, taxonomy and biogeography of Meso-Cenozoic Testudinata of the Argentine territory.

Key words. Testudinata. Triassic. Jurassic. Cretaceous. Palaeogene. Neogene. Quaternary. Argentina.

EL ESTUDIO de las tortugas extintas en el territorio argentino se inició en el año 1858 cuando el naturalista francés Auguste Bravard nominó la primera especie de tortuga. Desde ese entonces transcurrieron 157 años hasta la actualidad. Durante este período de tiempo, el conocimiento de los Testudinata del territorio argentino se incrementó en una progresión geométrica, desde las meras nominaciones de especies sin ningún tipo de caracterización, realizadas por los naturalistas y los pioneros de los estudios paleontológicos del siglo XIX, hasta los estudios anatómicos detalla- dos de la actualidad que han servido de base para efectuar análisis filogenéticos y estudios de biogeografía histórica. En este enorme periodo de tiempo que abarca desde mediados del siglo XIX hasta las primeras dos décadas del siglo XXI los estudios de las tortugas pueden ser divididos en tres etapas. Una etapa inicial en la cual los estudios fueron llevados a cabo por naturalistas extranjeros y argentinos, así como por pioneros de la paleontología argentina. Esta etapa fue la más extensa (más de 100 años) y se extendió desde 1858 hasta 1965. Una segunda etapa, extendida entre 1966 
y 1993, representa una etapa intermedia en la que se realizaron estudios de síntesis por parte de paleontólogos de vertebrados y por paleoherpetólogos argentinos y extranjeros. Finalmente una tercera y última etapa de estudio se desarrolló entre los años 1994 y 2015. Este tiempo se corresponde con la etapa más reciente en la que se realizaron estudios anatómicos más detallados sobre los que se construyeron análisis filogenéticos cladísticos y estudios biogeográficos realizados por especialistas argentinos. Este avance en el conocimiento sobre la taxonomía de las tortugas extintas argentinas se refleja no solo en el incremento en el número de trabajos publicados sino también por el aumento del detalle de los mismos. Tan es así es que en la primera etapa del estudio de las tortugas, que comprende más de 100 años, se publicaron 18 estudios en los que se hace referencia a tortugas fósiles, en muchos de ellos tan sólo como meros apéndices de estos trabajos. En la segunda etapa, que comprende 27 años, se editaron 18 trabajos y se presentó una tesis doctoral en la Universidad Nacional de La Plata (de la Fuente, 1988), mientras que en la última etapa se publicaron 64 trabajos y se defendieron dos tesis de grado en la Universidad de Buenos Aires (Maniel, 2011) y Universidad Nacional del Nordeste (Zacarías, 2012), dos tesis doctorales en la Universidad Nacional de La Plata (Bona, 2004; Sterli, 2009), y otras tres tesis doctorales están en curso en la Universidad de Buenos Aires (Lic. Ignacio Maniel), en la Universidad Nacional de La Plata (Lic. Gerardo Zacarías) y en la Universidad Nacional del Comahue (Lic. Juan Marcos Jannello).

Es importante destacar aquí el relieve que adquirió la Dra. Zulma Brandoni de Gasparini para la consolidación y el avance de las investigaciones sobre las tortugas fósiles argentinas en las dos últimas etapas de su desarrollo. Esto se manifiesta en los estudios de síntesis que efectuó la Dra. Brandoni de Gasparini sobre la herpetofauna cenozoica argentina y sudamericana en co-autoría con la Dra. Ana María Báez en sus tres primeros artículos (Gasparini y Báez, 1975;
Báez y Gasparini, 1977, 1979), o en co-autoría con los Dres. Marcelo de la Fuente y Oscar Donadío en un trabajo ulterior (Gasparini et al., 1986). Más relevante aún es el apoyo que Zulma Brandoni de Gasparini brindó a sus primeros discípulos. Es tan así que ella dirigió, hacia fines del siglo XX, las tesis doctorales de Marcelo S. de la Fuente y Marta S. Fernández sobre tortugas extintas y actuales, respectivamente. Posteriormente, al comienzo del siglo XXI, la Dra. Brandoni de Gasparini co-dirigió las tesis doctorales de Paula Bona y Juliana Sterli.

Este ensayo sobre la cronología de las investigaciones de las tortugas extintas complementa el estudio recientemente realizado por Cabrera (2014) sobre los orígenes y los progresos de los estudios neontológicos de quelonios argentinos.

\section{DESARROLLO}

\section{Etapa inicial: Estudios llevados a cabo por naturalistas y pioneros de la paleontología argentina (Fig. 1)}

El estudio de las tortugas extintas de la República Argentina se inicia a mediados del siglo XIX cuando Bravard en 1858 (Fig. 1), en su monografía sobre los terrenos marinos cenozoicos de las cercanías de Paraná publicado en El Diario Oficial "El Nacional Argentino", menciona, sin describir, a Emys paranensis. Esta especie fue incluida en un catálogo litografiado por él mismo en 1860 del que solo un extracto fue publicado en diferentes obras de Paul Gervais (fide Burmeister, 1885), el cual incluía solo la lista de mamíferos. Posteriormente este autor describe Emys paranensis con base en cuatro de los cinco fragmentos del caparazón coleccionados por Auguste Bravard en los afloramientos terciarios por él mencionados. Sobre la base del quinto fragmento, Burmeister (1885) nomina y describe brevemente un nuevo taxón denominado como Platemys torrentium (Fig. 1). De acuerdo al Código de Nomenclatura Zoológica, la autoría de los dos primeros taxones de tortugas nominados y descriptos en el territorio argentino corresponden a Bur-

Figura 1. Línea de tiempo que abarca más de 120 años de estudios sobre tortugas extintas en Argentina. En estos 120 años se diferencian dos etapas (inicial e intermedia). En la figura se muestran fotografías de los principales investigadores involucrados y años de publicación de los principales trabajos. Los círculos naranja representan trabajos principalmente sobre quélidos, los círculos violeta sobre testudínidos, los círculos verdes sobre meiolaniformes, los círculos azules sobre Notoemys laticentralis, y los círculos negros representan trabajos de síntesis. 


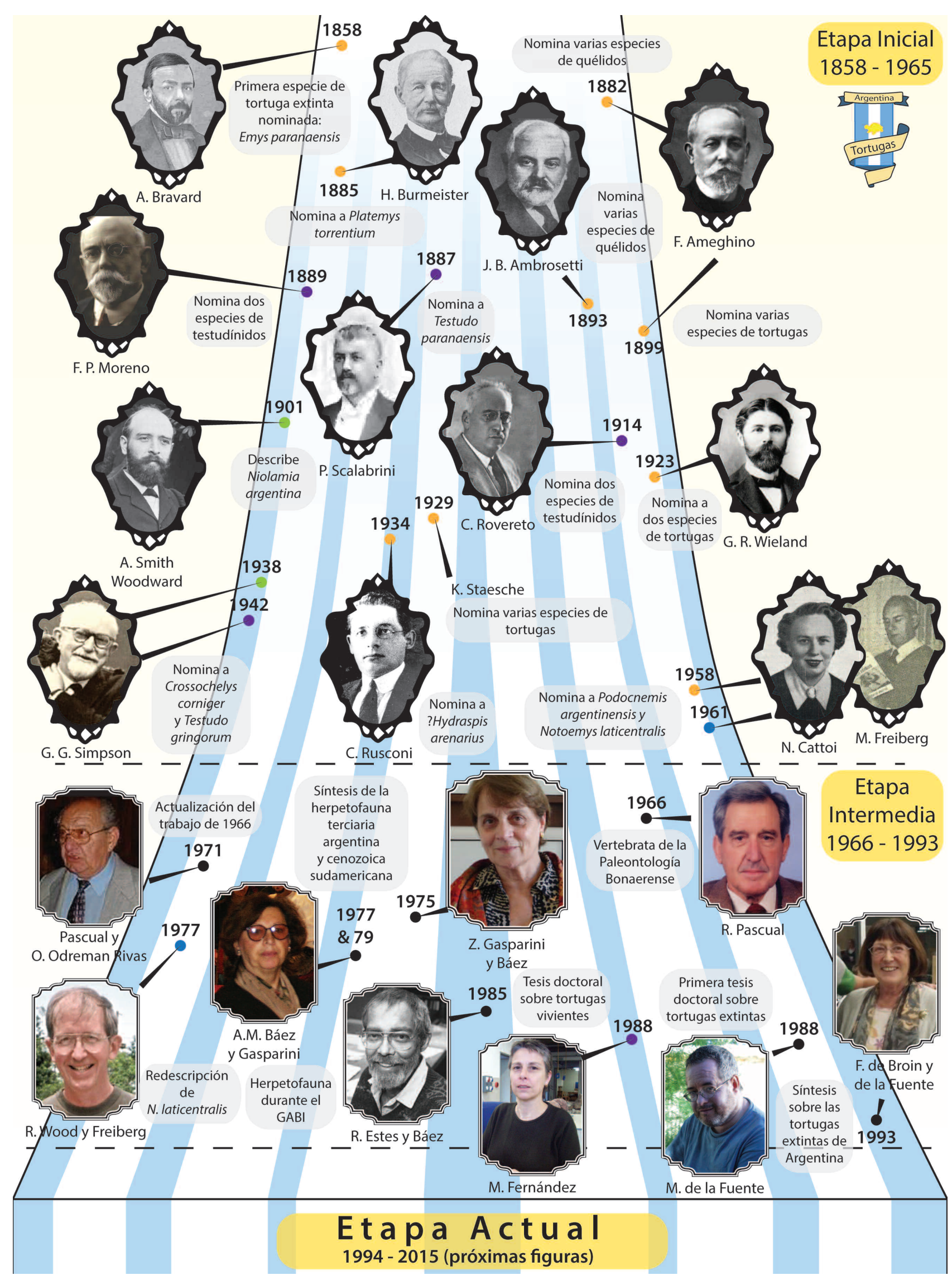


meister (1885). Dichos materiales recuperados por Bravard y estudiados posteriormente por Burmeister formaron parte de las colecciones del Museo Público de Buenos Aires, pero no se localizaron en las colecciones del actual Museo Argentino de Ciencias Naturales "Bernardino Rivadavia". Como estos taxones no cumplen con los requerimientos del Código Internacional de Nomenclatura Zoológica son considerados como nomina dubia (Maniel y de la Fuente, en prensa).

También Ameghino (1882) nominó cuatro taxones: Platemys laevis, P. robusta, P. antiqua y P. fossilis (Fig. 1). Los tres primeros procedían de la "Formación Pampeana" y el restante ( $P$. fossilis) de los depósitos "Postpampeanos antiguos". Cabe señalar que la "Formación Pampeana" de Ameghino se corresponde con las SALMA (South American Land Mammal Ages) Ensenadense y Lujanense y la "Formación Post-Pampeana" con el Holoceno. La revisión efectuada por de la Fuente (1988) en su tesis doctoral le permitió reconocer ejemplares de la especie Hydromedusa tectifera, representados por materiales fragmentarios del caparazón conservados en tapas de cartón atadas con "piolines" con los nombres de las especies mencionadas. Por lo tanto $P$. laevis, $P$. antiqua, $P$. robusta y $P$. fossilis fueron consideradas sinónimos junior de Hydromedusa tectifera (Rhodin et al., 2015; Maniel y de la Fuente, en prensa).

Posteriormente Ambrosetti (1893) dio a conocer cinco nuevas especies (Fig. 1), las que fueron referidas al género Platemys. De acuerdo con este autor las mismas procedían de "depósitos fluviales de la Formación Oligocena de Paraná". Estos depósitos posiblemente se correspondan con el denominado "Conglomerado osífero". De acuerdo con Cione et al. (2000), este horizonte está situado en la base de la Formación Ituzaingó, cuya fauna terrestre sugiere una edad Huayqueriense (Tartoniana). Ambrosetti (1893) sobre la base de las cinco primeras placas costales del caparazón dorsal correspondientes a otros tantos individuos describió e ilustró cinco nuevos taxones: Platemys entrerriana, P. bergii, P. mesopotamica, P. robusta y P. holembergii. Tomando en cuenta que los caracteres empleados por Ambrosetti (1893) son insuficientes e inadecuados para definir taxones de tortugas y que los materiales sobre los que fundó estos taxones no fueron localizados en su supuesto repositorio (actual Museo de Ciencias Naturales de Paraná), es poco probable que las placas descriptas por Ambrosetti se puedan referir al género Platemys. Esto se debe a que uno de los caracteres diagnósticos del género monotípico actual (Platemys platycephala) es la ausencia de placas neurales, las que según Ambrosetti (1893) estaban presentes en asociación con las placas costales (si bien él no las describió). Por lo expuesto y por no cumplir con los requerimientos del Código Internacional de Nomenclatura Zoológica en su nominación, se considera a las cinco especies de Ambrosetti como nomina dubia (Maniel y de la Fuente, en prensa).

Algunos años más tarde Ameghino (1899, p. 10) describió sucintamente tres nuevas especies referidas al género Platemys (P. guaranitica, P. patagonica y P. sehuensis) que de acuerdo con el autor procedían del "Cretácico de Patagonia" (Fig. 1). En este trabajo Ameghino no hace referencia a la localización geográfica y estratigráfica precisa de estas tortugas. No obstante, Ameghino (1900) al presentar una lista de la "Formación Guaranítica" menciona que Platemys guaranitica y $P$. patagonica procederían de los "Pisos Sehuense y Piroteriense" mientras que $P$. sehuensis procedería del "Piso Sehuense". Cabe destacar que de acuerdo con Marshall et al. (1983) al menos el "Piso Piroteriense" de Ameghino se correspondería con la SALMA Deseadense. Ameghino (1899, p. 10) caracterizó a los tres nuevos taxones de la siguiente forma: "Platemys guaranitica n. sp. algo más pequeña que Platemys hilarii actual y con la superficie ligeramente puntuada. Platemys patagonica n. sp., más grande que la especie actual y con la coraza con estructura vermicular profunda. Platemys sehuensis n. sp., sumamente pequeña y con coraza lisa, sin escultura de solo 3 a $4 \mathrm{~mm}$ de espesor." Lamentablemente Florentino Ameghino no ilustró ni brindó información adicional sobre los holotipos de estas especies, las cuales no han podido ser ubicadas en su supuesto repositorio, el Museo Público de Buenos Aires (actualmente Museo Argentino de Ciencias Naturales "Bernardino Rivadavia"). Asimismo, si bien Ameghino diferenció estos taxones por caracteres de relativa significación taxonómica (i.e., ornamentación y dimensiones de las placas óseas) no mencionó otros atributos en estos materiales que permitan efectuar una determinación por debajo de la categoría ordinal. Por lo tanto hasta que los holotipos de las especies mencionadas sean localizados se ha propuesto considerar estas tres especies como nomina dubia (Maniel y de la Fuente, en prensa y publicaciones allí citadas). Es in- 
teresante destacar que Sterli et al. (2015) reconocen que las tortugas acuáticas pertenecientes al clado Chelidae fueron extirpadas de Patagonia con posterioridad al Eoceno medio y por lo tanto el registro de quélidos oligocénicos es por lo menos cuestionable.

Scalabrini (1887) nominó sin definir, describir o ilustrar, una nueva especie de tortuga, Testudo paranensis, procedente de "las barrancas del Paraná", provincia de Entre Ríos (Fig. 1). Posteriormente Williams (1950) consideró a esta especie como nomen nudum criterio compartido por Auffenberg (1974) y de la Fuente (1988) por no cumplir con los requerimientos de disponibilidad del Código Internacional de Nomenclatura Zoológica. Pero, como en realidad este taxón fue nominado con anterioridad al año 1931 y los materiales no han podido ser localizados en su posible repositorio, el Museo de Ciencias Naturales de Paraná, debería considerarse como un nomen nudum (de la Fuente, 1988; de la Fuente y Zacarías, en prep.). Si bien Auffenberg (1974) consideró erróneamente que Testudo paranensis fue dada a conocer por Scalabrini (1884), ese autor en este artículo reproduce la conferencia pronunciada en la Sección Paraná del Instituto Geográfico Argentino. En este sentido, cabe mencionar que la primera mención de Testudo parenensis se encuentra en Scalabrini (1887).

Con posterioridad a que Scalabrini publicara su artículo, Moreno (1889) dio a conocer dos nuevas especies provenientes de la localidad de Monte Hermoso (provincia de Buenos Aires) (Fig. 1). Sobre la base de una gran parte de un caparazón dorsal, Pascasio Moreno nominó a Testudo australis, y sobre la base de fragmentos de placas del caparazón y de un plastrón, a Testudo formosa. El holotipo sobre el cual Moreno (1889) fundó Testudo australis fue localizado entre las colecciones de Paleontología de Vertebrados del Museo de La Plata (MLP 26-400), posibilitando a de la Fuente (1988, 1997a) validar este taxón. En lo que respecta a Testudo formosa cabe señalar que el material tipo sobre el cual Pascasio Moreno acuñó el nombre de este taxón nunca fue encontrado en su supuesto repositorio (Museo de La Plata). Esta circunstancia junto a la insuficiente información anatómica de esta especie suministrada por Moreno (1889), instó a de la Fuente (1988) a considerar a Testudo formosa como un nomen dubium.

Ameghino (1899) también publicó el nuevo taxón,
Trionyx argentina, con una breve e insuficiente caracterización del mismo, mencionando como procedencia el Cretácico de Patagonia ("Formación Guaranítica") (Fig. 1). En su obra de 1900 Florentino Ameghino se refiere a Tryonix [sic] argentina como proveniente del "Piso Sehuense" (Ameghino, 1900), pero en ninguno de sus trabajos indica la localidad donde el material fue recuperado. La Formación Guaranítica de Ameghino incluye horizontes marinos y continentales que se extienden desde el Cretácico hasta el Oligoceno y su "piso Sehuense". Sobre esta base Wood y Patterson (1973) consideraron la posibilidad de que Trionix argentina provendría del área tipo del "Piso Sehuense" (actualmente Formación Mata Amarilla) en el Río Sehuen, provincia de Santa Cruz. Por otra parte Wood y Patterson (1973) indicaron que Ameghino (1898) también incluyó en su "Piso Sehuense" depósitos de otras regiones distintas al área tipo, entre ellas a la región de Río Chico en la provincia de Chubut, por lo tanto su procedencia estratigráfica y geográfica es imprecisa. También lo es su asignación taxonómica ya que la "diagnosis" propuesta por Ameghino solo hace referencia a su pequeño tamaño, la ornamentación vermicular, la osificación incompleta y a la falta de escudos córneos. Como lo indicaran Wood y Patterson (1973), esta caracterización de la especie es completamente inadecuada para referir un espécimen al género Trionyx o incluso probar su asignación familiar. De hecho este tipo de ornamentación está presente en otros grupos de tortugas (i.e., Chelidae) y la ausencia de escudos epidérmicos en una placa no necesariamente significa la falta de escudos en el caparazón. Sobre la base de estos argumentos Wood y Patterson (1973) consideraron a Trionyx argentina como un nomen dubium.

También, Ameghino (1899) hace mención por primera vez de Niolamia argentina (una tortuga terrestre de gran tamaño que exhibe un cráneo con cornamenta) acuñando el nombre de esta especie (Fig. 1). Sin embargo, Florentino Ameghino no designa un holotipo, no diagnostica a la especie, ni ilustra el espécimen sobre el cual esta especie ha sido fundada. Este autor menciona que este espécimen fue descubierto por su hermano Carlos en la Formación Guaranítica (?Cretácico-Paleógeno), en la región comprendida entre los ríos Sehuen y Chubut (Ameghino, 1899). Durante ese mismo año, el aquel entonces director del Museo de La Plata, Francisco Pascasio Moreno, comunicó en una nota breve (Mo- 
reno, 1889) el hallazgo realizado por Santiago Roth de un anillo caudal, de restos del caparazón y de un cráneo, figurando por primera vez los materiales de esta tortuga. Dos años más tarde (Fig. 1), Woodward (1901) publica la descripción de esta especie ilustrando el cráneo y parte del postcráneo del mismo espécimen del que había previamente hecho referencia Moreno (1899). Smith Woodward, en su trabajo de 1901, incurre en un error en el nombre genérico con el que Florentino Ameghino nominó esta especie (ver discusión en Sterli y de la Fuente, 2011a) y menciona que Santiago Roth coleccionó restos de estos reptiles extintos en asociación con mamíferos, en estratos rojos que supuestamente podrían corresponder en antigüedad al Cretácico Tardío. Por otra parte, aportando más confusión sobre la procedencia de Niolamia argentina, Ameghino (1906) sugiere que la localidad donde Santiago Roth recuperó esta tortuga estaba localizada a $3 \mathrm{~km}$ al noroeste del Lago Colhue Huapi (actualmente Lago Musters) donde estaban expuestos afloramientos portadores de la fauna de mamíferos Notostylops. Esta aparente ambigüedad sobre la procedencia geográfica y estratigráfica y los presuntos colectores de Niolamia argentina se inscribe en la existencia de dos grupos antagónicos en pugna (uno liderado por Florentino Ameghino y otro por Francisco Pascasio Moreno) quienes se ocultaron información sobre la precisa procedencia de esta enigmática especie de tortuga con cornamenta (Sterli y de la Fuente, 2011a).

En su estudio "Los Estratos Araucanos y sus fósiles", Rovereto (1914) dio a conocer dos nuevas especies de testudínidos gigantes (Fig. 1): Testudo gallardoi procedente del "Araucanense" de Andalhualá en la provincia de Catamarca, y Testudo praestans del "Montehermosense" de la localidad homónima (Monte Hermoso) en la provincia de Buenos Aires. Rovereto distinguió estas especies por el diferente grado de desarrollo de las gibas vertebrales, ignorando las especies mencionadas por Francisco P. Moreno 25 años antes. Cabe destacar que a pesar de no contar con datos precisos de colección, de acuerdo a de la Fuente (1988, 1997a) es posible determinar que el "Araucanense" aflorante en Andalhualá corresponde al "Araucanense" sensu stricto= Formación Andalhualá (Riggs y Patterson, 1939; Marshall y Patterson, 1981). Asimismo, como Bossi y Palma (1982) lo indican, el nombre de la Formación Andalhualá proviene de la localidad homónima enclavada en los afloramientos de esta unidad litoestratigráfica. La misma ha sido asignada a la SALMA Huayqueriense (Mioceno Tardío) por su agregado de mamíferos (Marshall et al., 1983). Por otra parte, el holotipo de Testudo praestans procede de la Formación Monte Hermoso, tipo de la SALMA Montehermosense (Plioceno temprano-medio) expuesta a lo largo de los acantilados de la costa atlántica de la provincia de Buenos Aires, entre Monte Hermoso y Punta Alta (Marshall et al., 1983).

En 1923, Wieland (1923) describió en detalle el caparazón dorsal de un quélido el cual asignó al nuevo género y especie Parahydraspis paranensis (Fig. 1). Este ejemplar y otros restos coleccionados posteriormente por Santiago Roth y E. Sors a fines del siglo XIX , así como Gustavo Scillato Yané e Ignacio Noriega más recientemente, provendrían del Conglomerado osífero (= niveles basales de la Formación Ituzaingó SALMA Huayqueriene, Mioceno Tardío, Cione et al., 2000) aflorante en los acantilados de las proximidades de la ciudad de Paraná (provincia de Entre Ríos) (ver discusión en de la Fuente, 1992; Argañaraz y Piña, 2000; Rhodin et al., 2015; Maniel y de la Fuente, en prensa). En el mismo trabajo Wieland nominó el taxón Chelys (?) patagonica procedente de alguna localidad indeterminada del sur de Patagonia. Este autor fue ambiguo en cuanto a sus consideraciones taxonómicas ya que advirtió algunas similitudes de este taxón con el quélido actual Chelus fimbriata, pero al mismo tiempo reconoció caracteres compartidos con los testudínidos. Este espécimen fue referido al género Chelonoidis por Joyce y Faux (2008).

En 1929 el paleontólogo alemán Karl Staesche (Fig. 1) dio a conocer la fauna de quelonios de niveles de antigüedad daniana de la unidad litoestratigráfica que actualmente se conoce como Formación Salamanca (asignada al Cretácico Superior en su obra). Staesche (1929) nominó y describió nuevos taxones de pleurodiros y "criptodiros" sobre la base de placas óseas fragmentarias del caparazón dorsal y plastrón, recuperados de los afloramientos de esta formación en Punta Peligro (provincia de Chubut). Staesche (1929) indicó la presencia de distintas especies de pleurodiros bothremídidos asignados a Najadochelys, N. patagonica $\mathrm{n}$. sp., Najadochelys cf. patagonica n. sp., y ?Najadochelys maior n. sp. Asimismo, Staesche (1929) también reconoció la presencia en esta fauna de Punta Peligro de dos especies de 
"criptodiras": Osteopygis sculptus y cf. Gyremys. Staesche (1929) se refirió al género Naiadochelys acuñado por Hay (1908) pero lo escribió incorrectamente como Najadochelys. Trabajos realizados en tiempos recientes han sugerido que las especies de Staesche son todas referibles al clado PanChelidae (Broin y de la Fuente, 1993 a,b; Bona et al., 1998) e incluso a géneros extintos de este clado tales como Yaminuechelys o Salamanchelys (Bona y de la Fuente, 2005; Bona, 2006).

Rusconi (1934) dio a conocer una nueva especie de tortuga ?Hydraspis arenarius (Fig. 1) procedente de sedimentitas atribuidas a la Formación Puelche, Santa Cruz (1972) en Villa Ballester (provincia de Buenos Aires). Como todos los vertebrados de esta unidad, los restos fueron extraídos mediante operaciones de perforación utilizando bombas de succión (Cione et al., 2000) sin ningún tipo de control estratigráfico. Tal es así que en la misma unidad aparecen vertebrados marinos de la Formación Paraná y del "Conglomerado osífero" junto con vertebrados terrestres. Rusconi (1934) nominó esta especie sobre la base de un fragmento de placa costal 1 con ornamentación moderada. Posteriormente, sin razones explícitas, Kuhn (1964) refirió este taxón al género australasiático Chelodina. De acuerdo a de la Fuente $(1988,1992)$ el espécimen sobre el cual Carlos Rusconi fundó la especie no muestra caracteres diagnósticos que permita referirlo a algún género particular del clado Pan-Chelidae, por lo cual Maniel y de la Fuente (en prensa) refieren a ?Hydraspis arenarius como un nomen dubium.

Como resultado de los trabajos de campo liderados por el Prof. Dr. George Gaylord Simpson a Patagonia a principios de los años 30 del siglo XX se exhumaron diversos restos de reptiles (entre otros grupos de vertebrados) que fueron estudiados por el mismo Simpson en años ulteriores. Entre estos, Simpson (1938) describió con gran detalle los restos craneanos de la segunda tortuga con cornamenta (clado Meiolaniidae) conocida hasta ese tiempo en América del Sur (Fig. 1). Dicha especie, dada a conocer como Crossochelys corniger procede de afloramientos correspondientes al SALMA Casamayorense (Eoceno Medio) de la provincia de Chubut. Posteriormente, en el año 1942 Simpson describió la nueva tortuga terrestre Testudo gringorum del Mioceno Inferior de la provincia de Chubut (Simpson, 1942) y se constituyó en uno de los registros de testudínidos más antiguos de Sudamérica para ese entonces (Fig. 1). Simpson (1943) en su obra "Turtles and the origin of the fauna of Latin America"resume la información disponible sobre la distribución presente y pasada de las tortugas neotropicales familia por familia haciendo referencia a diversos taxones de tortugas registrados en nuestro territorio. Simpson (1943) también sostiene, desde un punto de vista paleobiogeográfico, que las tortugas neotropicales se pueden incluir en cuatro categorías: (1) formas extintas, fuertemente especializadas y aberrantes, muy diferentes a las tortugas extintas de la región Holártica (i.e., Niolamia, Crossochelys); (2) formas endémicas antiguas que han tenido ancestros en el Cretácico Tardío en América del Sur (i.e., pelomedúsidos y quélidos); (3) tortugas terrestres que arribaron a América del Sur por deriva pasiva cuando este continente se encontraba aislado (i.e., testudínidos) y (4) miembros de la fauna de quelonios de América del Norte que arribaron a Sudamérica una vez que se estableció el istmo panameño (i.e., Chelydridae, Kinosternidae, Emydidae).

Hacia fines de los años 50 del siglo XX la paleontóloga Noemí Cattoi (en ese entonces a cargo de la Sección Paleontología Vertebrados del Museo Argentino de Ciencias Naturales "Bernardino Rivadavia" de Buenos Aires), y el herpetólogo Marcos Freiberg (Fig. 1) se abocaron al estudio de los quelonios extinguidos de la colección del Museo Argentino de Ciencias Naturales. En una primera etapa describieron el primer podocnemídido ("Podocnemis" argentinensis) del territorio argentino (Cattoi y Freiberg, 1958). El mismo consiste en un plastrón prácticamente completo coleccionado por el Dr. Otto Schlagintweit que procedería, según estos autores, de la parte media de las "Margas Multicolores" expuestas en la quebrada Queñoal, en el flanco occidental del espolón Esquina Blanca, Quebrada de Humahuaca, provincia de Jujuy (Gasparini y Báez, 1975; Broin y de la Fuente, 1993 a,b), horizonte actualmente considerado como Formación Maíz Gordo (Pascual et al., 1981) referido al Cretácico por Cattoi y Freiberg (1958) y actualmente considerado Paleoceno superior (Gayet et al., 1991).

Posteriormente, Cattoi y Freiberg (1961) describieron la primera tortuga jurásica marina que fuera localizada por el Dr. Osvaldo Reig incluida en una laja utilizada para revestimiento en una casa de la localidad bonaerense de Acasusso (Wood y Freiberg, 1977) y donada por O. Reig al Museo 
Argentino de Ciencias Naturales de Buenos Aires. Cattoi y Freiberg dieron a conocer en 1961 este quelonio como Notoemys laticentralis, en ese entonces la tortuga más antigua de América del Sur. Gracias a la particularidad de la roca portadora del fósil, se pudo determinar que provenía de las calizas litográficas de una cantera del área de Manzano Escondido (provincia de Neuquén), de la Formación Vaca Muerta, Jurásico Tardío (Gasparini et al., 2015a) y no de la localidad Las Lajas como autores previos lo habían sugerido (i.e., Wood y Freiberg, 1977; de la Fuente y Fernández, 1989; de la Fuente, 2007).

\section{Etapa intermedia: Estudios de sintesis realizados por paleontólogos de vertebrados y paleoherpetólogos argentinos y extranjeros (Fig. 1)}

Esta segunda etapa se inicia en 1966 (Fig. 1) con la publicación del Fascículo IV "Vertebrata de la Paleontografía Bonaerense" escrito por Pascual y colaboradores. Esta es una magnífica obra de compilación sobre los vertebrados de la provincia de Buenos Aires en la que también se esbozan, en un capítulo introductorio, las edades del Cenozoico mamaliano de la Provincia de Buenos Aires. En esta monografía Cattoi (en Pascual, 1966) asume la autoría de la parte de reptiles en la que se presentan detalladas diagnosis de la familia Testudinidae, de la subfamilia Testudininae y del género Geochelone, así como también de la familia Chelidae y del género Phrynops. De todos estos taxones se indica la distribución cronológica y geográfica global y la distribución estratigráfica en la provincia de Buenos Aires, y se reproduce solamente en la lámina IV la ilustración del caparazón y plastrón de "Geochelone" praestans de Rovereto (1914).

Posteriormente Pascual y Odreman Rivas (1971) presentan una actualización del trabajo que el Prof. Dr. Rosendo Pascual presentara en el IV Congreso Latinoamericano de Zoología realizado en la ciudad de Caracas en 1968 (Fig. 1). En esta obra los autores hacen referencia al registro de los vertebrados cenozoicos de la República Argentina, destacando el predominio de mamíferos sobre los demás vertebrados. Con el objeto de aportar datos para incrementar el conocimiento sobre la evolución de los ambientes del extremo sur del continente sudamericano durante el Cenozoico, los autores mencionados destacaron aspectos rela- cionados a la situación geográfica de los yacimientos de vertebrados de Argentina. En este sentido Pascual y Odreman Rivas (1971) destacan que desde el Paleoceno y hasta el Mioceno el registro de vertebrados es exclusivamente patagónico, con otros seis registros en bajas latitudes del territorio argentino. Estos autores consideran también que a partir del Plioceno el registro se confina casi al territorio situado al norte de Patagonia. Posteriormente este trabajo discurre en detalladas listas de especies referidas a diferentes familias, órdenes y clases de distintos grupos de vertebrados, desde aquellos del "Salamanquense", pasando por los de Edad Casamayorense, otros de Edad Mustersense, así como aquellos de edades Deseadense, Divisaderense, Colhuehuapense, "Patagoniense", Santacrucense, Friasense, Chasiquense, Huayqueriense, "Mesopotamiense", "Enterriense" y "Rionegrense" del Río Paraná (Entre Ríos), así como los de la Edad Montehermosense. Acompañando a las listas taxonómicas presentadas, Pascual y Odreman Rivas (1971) se destacan sucintamente las condiciones ambientales de cada edad y se indican los aspectos más destacados de los diferentes componentes de la comunidad de vertebrados de las distintas edades reconocidas por los autores (peces, anfibios, reptiles, aves y mamíferos). Todas las especies de tortugas cenozoicas conocidas para las edades indicadas, son mencionadas con el "status" taxonómico conocido para ese entonces.

Síntesis más específicas se inician con el importante trabajo de Gasparini y Báez (1975) (Fig. 1). En este estudio las autoras mencionadas ofrecen un panorama sobre el estado del conocimiento del registro paleontológico de los anfibios y reptiles que habitaron el territorio argentino durante el Cenozoico. En la primera parte de esta obra las autoras listan todo el material registrado en el Cenozoico argentino hasta ese momento. Dicho material fue ordenado cronológicamente por Época y Edad Provincial, y de acuerdo a su procedencia geográfica. Antes de iniciar el estudio del material asignado a una época determinada, realizan un sucinto comentario sobre las áreas en donde están expuestas las sedimentitas portadoras de los taxones estudiados, emitiendo comentarios sobre las condiciones paleoambientales en donde fueron depositadas. Para cada registro se efectúa la determinación más precisa posible del material disponible, vertiéndose comentarios taxonómicos o de otra 
índole en el ítem observaciones. Así como se tratan otros anfibios y reptiles, se efectúan comentarios sobre las especies paleocenas "salamanquenses" de tortugas como Naiadochelys patagónica, ? Naiadochelys maior, Osteopygissculptus nov. gen. cf. Gyremys nominadas por Steasche (1929), Testudines "riochiquenses" indeterminados de Patagonia, podocnemididos de NOA como Podocnemis argentinensis (como pelomedúsidos en ese trabajo) y material probablemente referible a esta familia asignado como Testudines indeterminados, especies eocenas casamayorenses como el meiolániido Crosochelys corniger o como el quélido Hydromedusa sp., Testudines indeterminados divisaderenses de Mendoza, la especie miocena Geochelone gringorum del Patagoniense de Patagonia central, cf. Geochelone gringorum del Friasense de Patagonia, Geochelone sp. del Hayqueriense de Catamarca, la especie Parahydraspis paranensis nominada por Wieland en 1923 y Geochelone sp. del "Mesopotamiense" de Entre Ríos, y la especie pliocena Geochelone preastans de la provincia de Buenos Aires.

En línea con el trabajo previo, Báez y Gasparini (1977) extendieron su revisión a los hallazgos paleoherpetológicos del Cenozoico sudamericano, destacando el aporte de los mismos al conocimiento sobre la evolución de los grupos tratados y a los paleoambientes habitados por los especímenes estudiados (Fig. 1). En la primera parte de esta obra las autoras indican los registros ordenados cronológicamente, enfatizando los datos disponibles sobre su procedencia estratigráfica y geográfica. Los aspectos relacionados sobre los orígenes y la evolución de los distintos grupos de anfibios y reptiles tratados en este estudio son abordados posteriormente. En términos generales las tortugas del registro cenozoico argentino mencionadas en Gasparini y Baéz (1975) son tratadas en esta obra. Entre las conclusiones aportadas por Báez y Gasparini (1977) se destacan: (1) los registros más antiguos de anfibios y reptiles del Cenozoico de Sudamérica son del Paleoceno inferior y corresponden a registros de cocodrilos y tortugas; (2) la mayor parte de las familias con registros en el Terciario inferior integran la herpetofauna neotropical en la actualidad con la excepción de los meiolániidos y sebécidos; (3) la antigüedad de ciertos grupos y la distribución geográfica pasada y presente de los mismos sugieren que la deriva continental ha jugado un rol importante en la evolución de muchos grupos de anfibios y reptiles sudamericanos; (4) la herpetofauna de América del Sur parece haber sido muy diferente de la existente en América del Norte; (5) durante gran parte del Cenozoico y previamente a la conexión de las américas se incorporan al elenco faunístico nuevas familias tales como: Testudinidae, Trionychidae, Colubridae, Nettosuchidae y posiblemente Emydidae; (6) numerosas familias de anfibios y reptiles no se hallan representadas en el registro paleontológico e incluso algunas de ellas como Plethodontidae, Ranidae, Chelydridae, Kinosternidae y Viperidae habrían colonizado tardíamente Sudamérica, mientras que otras (aunque no están registradas) por el grado de endemismo y las relaciones filogenéticas parecen ser antiguos integrantes de la herpetofauna sudamericana.

Otra contribución importante en la que se realiza una evaluación del registro fósil de la Herpetofauna sudamericana es la de Baéz y Gasparini (1979) (Fig. 1). En este trabajo se compila la información disponible en ese tiempo sobre el registro de los taxones extintos de anfibios y reptiles que conforman la actual herpetofauna sudamericana. En este estudio las autoras ponen especial énfasis en valorar la contribución de este registro en el desarrollo histórico de los diferentes clados de herpetos reconocidos en América del Sur. Integran estos resultados en un contexto paleogeográfico actualizado desde el Mesozoico medio hasta la actualidad, tomando en consideración los principales eventos diastróficos producidos desde fines del Cretácico a la actualidad en Sudamérica y el impacto de los mismos en los cambios fisiográficos que modelaron la composición y distribución de los anfibios y reptiles de este continente. Las conclusiones obtenidas en este trabajo sobre la composición y el origen de diferentes familias de anfibios y reptiles en Sudamérica están en consonancia con el aporte realizado por Báez y Gasparini (1977). En esta misma temática se inscribe el trabajo de Gasparini et al. (1986) en que se presenta un sucinto raconto de la herpetofauna cenozoica argentina.

Otro estudio de singular relevancia es el de Estes y Báez (1985) (Fig. 1). En este trabajo se evalúan los registros paleontológicos de anfibios y reptiles en el marco del Gran Intercambio Biótico Americano (GABI según sus iniciales en idioma inglés) durante el Neógeno y los previos durante el Cretácico y Paleógeno. Esta revisión evidencia que a pesar del limitado registro fósil es destacable la diferencia entre 
las herpetofaunas de América del Norte y Sudamérica que se extiende en el pasado. Estes y Báez (1985) identifican solo dos períodos de claro intercambio de faunas entre América del Norte y Sudamérica. El primero corresponde al Cretácico Tardío y está documentado directamente por la presencia de serpientes aníllidas y dinosaurios hadrosauridos e indirectamente por las distribuciones de lagartos teiidos y probablemente por caimanes aligatóridos. El segundo período correspondería al Mioceno con probables evidencias de intercambio entre los anuros leptodactílidos, los lagartos "iguánidos" y teiidos, las tortugas trionyquidas y los cocodrilos. Estos autores presentan como un apéndice de su trabajo un listado en el que se incluyen 30 localidades cretácicas, 23 localidades paleógenas y 22 neógenas con vertebrados "inferiores" en América del Sur, entre las cuales citan varias con registros de tortugas fósiles, 10 de estas locaciones con quelonios están señaladas en el territorio argentino (Estes y Báez, 1985: figs. 3-5).

En el año 1993 Broin y de la Fuente (Fig. 1) presentan las primeras síntesis detalladas de la fauna de quelonios de Argentina en una versión preliminar y en otra más completa (Broin y de la Fuente, 1993a,b). Esta última consistió en una breve enumeración de las formas recientes localizadas en las provincias argentinas con datos de procedencia geográfica, estratigráfica y antigüedad para las formas fósiles, indicando las primeras apariciones de los taxones actuales en el registro paleontológico. Estos autores mencionan que la queloniofauna Reciente del territorio argentino está compuesta de tortugas criptodiras laurasiáticas con respecto a su origen (un género con dos especies de testudínidos, una especie de emydido y otra de kinostérnido) y pleurodiras gondwánicas en cuanto a su diferenciación (quélidos con tres géneros y seis especies). En ese trabajo se provee una lista siguiendo un orden estratigráfico de localidades con el registro de los taxones determinados. El desarrollo de las dos partes y la conclusión de esta obra llevó a los autores (Broin y de la Fuente, 1993b) a presentar un panorama general de la fauna de tortugas de Argentina respecto de las formas sudamericanas, indicando setenta localidades distribuidas desde el Jurásico Tardío hasta el Holoceno. La primera localidad señalada en este trabajo corresponde a afloramientos titonianos de la provincia de Neuquén con taxones extintos parathetysianos. Luego durante el Cretá- cico de Patagonia con los primeros registros de quélidos y meiolániidos (ahora considerados meiolaniformes), y pelomedusoides en mucha menor proporción. En el Paleoceno y el Eoceno temprano los quélidos y meiolániidos persisten en Patagonia, mientras que en las provincias del NOA se registran pelomedusoides como en las Cuencas Andinas Norteñas (Bolivia y Perú) y en Brasil. Los quélidos invaden progresivamente Argentina hacia el norte y siguen colonizando el norte de América del Sur penetrando en países colindantes de Argentina (Brasil) y países del norte de América del Sur (Colombia, Venezuela). Así, los primeros registros de quélidos en bajas latitudes se registran en el Oligoceno de Brasil, luego en el Mioceno de Colombia, Brasil y Venezuela. En el Oligoceno-Mioceno estas tortugas desaparecen de las provincias más meridionales de Argentina (Patagonia). Esto parece ser resultado del cambio climático producido en estas áreas ligadas a la orogenia andina y el cambio de la disposición de las zonas tropicales alrededor del globo producido por el cambio en la disposición de los polos de rotación de la Tierra. Broin y de la Fuente (1993b) también sostienen que en los tiempos oligocenos-miocenos se constatan los primeros registros de los testudínidos laurasiáticos en Patagonia Argentina y en Bolivia (Broin, 1991). Estas verdaderas tortugas terrestres persisten en el extremo sur de Sudamérica hasta tiempos más recientes, a diferencia de los quélidos que son extirpados de Patagonia debido a su incapacidad para adaptarse al deterioro climático acontecido en el sur del territorio argentino. Durante el Cenozoico tardío (Mioceno medio-Pleistoceno), como sucede a nivel global, formas gigantescas de testudínidos referidos al género sudamericano Chelonoidis se registran en Argentina, acompañadas de especies de pequeñas dimensiones. Una de estas especies de pequeño tamaño (Chelonoidis chilensis) se extiende actualmente hasta el sur de la provincia de Río Negro, mientras que otras formas recientes (i.e., Chelonoidis carbonaria) no traspasaron más allá del noreste de Argentina. Desde América del Norte no solo se habría producido el probable ingreso de los testudínidos, sino también de un emydido con registro pleistoceno y un kinostérnido actual. Otros países del norte de América del Sur también fueron invadidos por geoemydinos y chelydridos.

Broin y de la Fuente (1993b) también enfatizaron la importancia de los caracteres de las vértebras cervicales para 
diferenciar distintos grupos de Pleurodira (Chelidae versus diferentes clados de Pelomedusoides), para ayudar a interpretar la evolución de los caracteres del cráneo y del caparazón. Esto, según los autores mencionados, sucede en el Cretácico y Paleoceno de Patagonia en donde varios taxones son reconocidos como quélidos "primitivos" estrechamente relacionadas con taxones vivientes de todos los diferentes clados reconocidos en el clado Chelidae. Finalmente Broin y de la Fuente (1993b) sostuvieron que durante el Cretácico-Eoceno en Patagonia se desarrolló una fauna surgondwánica (Chelidae, Meiolaniformes), mientras que en las provincias del norte de Argentina y otros países de Sudamérica (Bolivia, Brasil, Colombia, Venezuela) se desarrolló una fauna norgondwánica de Pelomedusoides como en África, Europa sur-occidental y en India. El trabajo de Broin y de la Fuente (1993b) marcó una inflexión en el estudio de las tortugas argentinas, porque el mismo sirvió de base para iniciar el estudio sistemático de las tortugas fósiles del territorio nacional.

Durante esta etapa también se defendió la primera tesis doctoral sobre tortugas fósiles en Argentina (de la Fuente, 1988), en donde se presentó el estudio taxonómico de las tortugas criptodiras de la familia Testudinidae y las pleurodiras de la familia Chelidae. En dicha tesis también se discuten algunos aspectos relacionados con el origen de estos dos diferentes clados de tortugas. También trabajos taxonómicos puntuales sobre quélidos (de la Fuente, 1986, 1992), sobre meiolániidos (de la Fuente y Fernández, 1992) y sobre testudínidos (de la Fuente y Cabrera, 1988; de la Fuente, 1994, 1997a,b) cenozoicos fueron publicados en este período o en años posteriores.

Acompañando a estos trabajos de síntesis también se han publicado trabajos descriptivos sobre especies particulares. Por ejemplo, Wood y Freiberg (1977) efectúan la redescripción del holotipo de la tortuga jurásica Notoemys laticentralis de la Formación Vaca Muerta (Fig. 1). En ese momento esta tortuga fue considerada como la tortuga más antigua de América del Sur y referida por estos autores a la familia Plesiochelyidae. Posteriormente de la Fuente y Fernández (1989) corrigieron esta asignación y la refirieron al clado Pleurodira.

En este período también se efectuaron descubrimientos de tortugas fósiles mesozoicas que adquirieron gran rele- vancia para alcanzar un conocimiento más detallado de la composición de la fauna de quelonios del territorio argentino y sobre los cuales realizar estudios a posteriori sobre la taxonomía, filogenia y paleobiogeografía de diversos grupos de Testudinata. Muchos de estos significativos hallazgos fueron motorizados por los extensivos trabajos de campo desarrollados por el Dr. José F. Bonaparte y colaboradores en afloramientos el Cretácico y Paleoceno de $\mathrm{Pa}$ tagonia durante las décadas del 80 y 90 del siglo pasado (ver Broin, 1987). Entre estos descubrimientos se inscriben los correspondientes a nuevos ejemplares de tortugas jurásicas como Notoemys laticentralis y Neusticemys neuquina realizados por el grupo liderado por la Dra. Gasparini en Cuenca Neuquina (Fernández y de la Fuente, 1993; Gasparini et al., 1997, 1999), el del ejemplar más completo de un quélido cretácico (Yaminuechelys gasparinii) realizado por la Dra. Teresa Manera de Bianco en afloramientos fini-cretácicos de Río Negro y el fantástico hallazgo de tortugas triásicas (Palaeochersis talampayensis) efectuado en la provincia de La Rioja por parte del Dr. Guillermo Rougier y colaboradores.

\section{Etapa actual: Estudios anatómicos, filogenéticos y paleobiogeográficos realizados por especialistas argentinos (Figs. 2-3)}

Muchas de las tortugas recuperadas durante las décadas de 1980 y 1990 sirvieron de material de base para que investigadores argentinos abordaran sus análisis ya no solo desde un punto de vista descriptivo, sino también sistemático-filogenético. En este sentido Fernández y de la Fuente (1994) abordan el estudio del ejemplar más completo de Notoemys laticentralis, el único stem Pleurodira (Pan Pleurodira sensu Joyce et al., 2004) conocido hasta el momento por material craneano y post-craneano. Este estudio fue complementado por el realizado por Lapparent de Broin et al. (2007). En el año 1995 se publica el primer trabajo sobre la tortuga más antigua de América del Sur. Esta tortuga, nominada como Palaeochersis talampayensis y preservada por material craneano y postcraneano de varios individuos, representa a un Testudinata basal estrechamente emparentado con Australochelys africanus del Jurásico Inferior de Sudáfrica (Rougier et al., 1995). Dicho trabajo se complementó con un trabajo de divulgación (Rougier et al., 1998) 

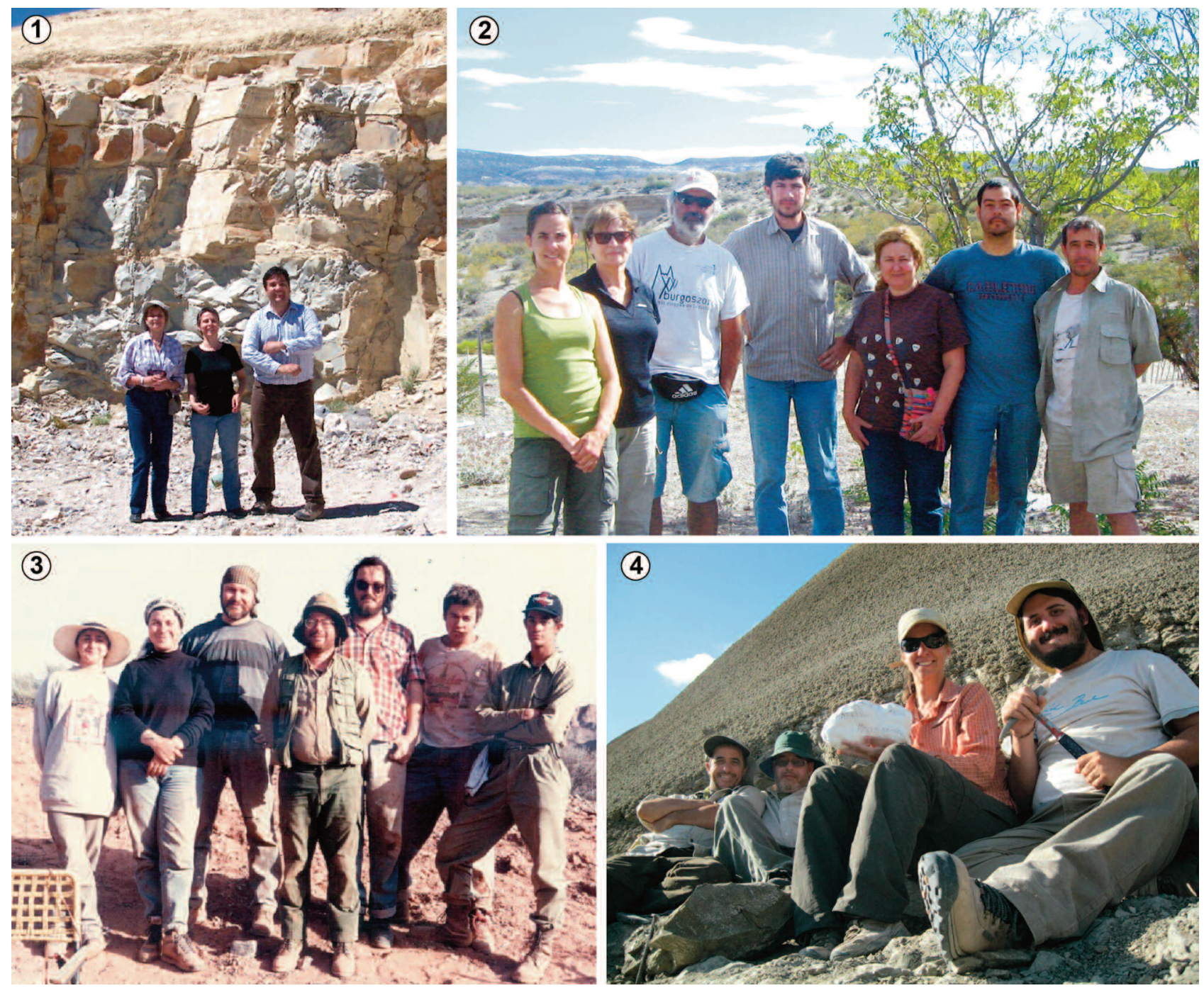

Figura 2. Campañas paleontológicas donde se han recuperado restos de tortugas extintas donde ha participado la Dra. Gasparini o algunos de sus discípulos. 1, Campaña en la cantera El Ministerio, Neuquén (Miembro Los Catutos de la Formación Vaca Muerta), septiembre de 2009. De izquierda a derecha: Zulma B. de Gasparini, Marta Fernández, y Alberto Garrido. 2, Campaña a la Formación La Colonia (Chubut), noviembre de 2011. De izquierda a derecha: Juliana Sterli, Zulma B. de Gasparini, Leonardo Salgado, José O'Gorman, Ana Parras, Julio Varela y Pablo Puerta. 3, Campaña a la Formación Los Colorados, septiembre 1994. De izquierda a derecha: Miriam colaboradora del MACN, Andrea Arcucci, Guillermo Rougier, Marcelo de la Fuente, Fernando Abdala, Diego Pol, Santiago Reuil. 4, Campaña a la Formación Salamanca, enero 2013. De izquierda a derecha: Pablo Puerta, Marcelo de la Fuente, Juliana Sterli, Ignacio Maniel.

y con una descripción de detalle del holotipo y de un material craneano referido (Sterli et al., 2007). En el mismo año que se dio a conocer Palaeochersis talampayensis se describieron los primeros restos de tortugas procedentes del Eoceno de la Península Antártica (de la Fuente et al., 1995), los cuales consistían en osículos dérmicos de la coraza secundaria, embebida en una piel correosa de una tortuga marina Dermochelyidae. Otro tipo de tortuga con caparazón prima- rio fue descripta posteriormente por Bona et al. (2010), año en el que también se describieron los restos del caparazón dorsal del primer queloniodeo del Cretácico Tardío de la Península Antártica (de la Fuente et al., 2010).

De la Fuente y Casadío (2000) describieron el primer stem Chelonioidea del territorio argentino cuando nominaron a Pampaemys meridionalis procedente del Daniano de La Pampa. Estos autores sugirieron afinidades con la especie 
Erquelinesia gosseleti del Ypresiano de Europa sobre la base de la parte posterior del cráneo preservado. Posteriormente una mandíbula y restos post-craneanos de otro espécimen fueron recuperados de niveles danianos en la provincia de Río Negro (de la Fuente et al., 2009). La asignación genérica de esta especie ha sido discutida por diversos autores (i.e., de la Fuente y Casadío, 2000; de la Fuente et al., 2009; Parham y Pyenson, 2010). Otros quelonioideos están representados solo por placas epitecales secundarias de la coraza de un Dermochelyidae, recuperadas del Mioceno de Patagonia (de la Fuente y Vucetich, 1998).

Otro hito importante lo constituyó la descripción del quélido cretácico más completo conocido hasta el momento. El mismo está representado por un espécimen preservado por su cráneo, vértebras cervicales, caudales, caparazón dorsal, plastrón y restos del esqueleto apendicular, referido por de la Fuente et al. (2001) al nuevo taxón Yaminuechelys gasparinii. De la Fuente et al. (2001) sugirieron que esta especie estaba estrechamente relacionada con las especies actuales del género Hydromedusa sobre la base de caracteres derivados del cráneo y las vértebras cervicales. Esta asunción fue corroborada por Bona y de la Fuente (2005) quienes propusieron que Yaminuechelys es el taxón hermano de Hydromedusa cuando describieron Yaminuechelys maior del Daniano de Chubut. Cabe destacar que una mayor antigüedad y diversidad para el género Yaminuechelys ha sido recientemente documentada (de la Fuente et al., 2010; de la Fuente et al., 2015, en prep.; Gasparini et al., 2015b).

Un gran número de taxones de pleurodiros cretácicos y paleógenos fueron descriptos con posterioridad al 2000. Entre ellos podemos mencionar a los quélidos Bonapartemys bajobarrealis, Prochelidella argentinae, Lomalatachelys neuquina, Paleophrynops patagonicus los cuales fueron descritos por Lapparent de Broin y de la Fuente (2001), Hydromedusa casamayorensis nominado por de la Fuente y Bona (2002), Prochelidella portezuelae nominado por de la Fuente (2003), Linderochelys rinconensis por de la Fuente et al. (2007), Prochelidella cerrobarcinae por de la Fuente et al. (2011) y Salamanchelys palaeocenica por Bona (2006), así como el podocnemidoideo Portezueloemys patagonica por de la Fuente (2003). Este último taxón ha sido considerado como el taxón hermano de los Podocnemididae (de la Fuente, 2003), de todos modos especímenes con cráneos mejor preservados permitirán corroborar o refutar esta hipótesis.

Diversos estudios taxonómicos sobre testudinoidos neógenos y pleistocénicos fueron publicados desde el inicio de este tercer período. Entre estos podemos mencionar la descripción de nuevos especímenes de Chelonoidis gringorum del Mioceno de Patagonia (de la Fuente, 1994), redescripción de holotipos de testudínidos gigantes del Mioceno y Plioceno de Argentina (de la Fuente, 1997a), así como también de especies actuales y extintas de testudínidos pleistocénicos de diferentes dimensiones (de la Fuente, 1997b; Noriega et al., 2000; Manzano et al., 2009; Zacarías et al., 2013, 2014), de emídidos (de la Fuente et al., 2002; Zacarías et al., 2014). Algunos de estos trabajos sobre tortugas pleistocénicas fueron complementados en su momento por un estudio de síntesis sobre reptiles cuaternarios (de la Fuente, 1999).

Algunos pocos estudios sobre Pelomedusoides cretácicos y paleógenos del noroeste de Argentina han sido publicados (de la Fuente y Lapparent de Broin, 1997; de la Fuente et al., 2003; de la Fuente en Scanferla et al., 2011) quedando por estudiar un buen número de materiales inéditos (de la Fuente et al., en prep.) en un área del territorio argentino que es potencialmente rica en restos de quelonios podocnemídidos (e.g., Pascual et al., 1981). La radicación del Dr. A. Scanferla y del Lic. Gerardo Zacarías en el instituto IGIBEO dependiente del CONICET y de la Universidad Nacional de Salta garantizará la continuidad de las prospecciones en estos ricos yacimientos paleógenos del NOA, iniciados por el Dr. Rosendo Pascual y equipo de colaboradores a finales de la década de 1970.

Los trabajos de campo llevados a cabo en forma conjunta por el Dr. Guillermo Rougier y paleontólogos del Museo Egidio Feruglio de Trelew en los afloramientos del Jurásico inferior-medio de Cerro Cóndor (provincia de Chubut) dieron por resultado el hallazgo, entre otros vertebrados, de una tortuga Pan-Testudines estrechamente relacionada con Kayentachelys aprix del Jurásico inferior de Arizona (Gaffney et al., 1987; Sterli y Joyce, 2007) y con Indochelys spatulata del Jurásico Inferior de la India (Datta et al., 2000). Dicha tortuga, consistente en varios ejemplares preservados por restos craneanos y postcraneanos, fue nominada como Condorchelys antiqua (Sterli, 2008) y fue objeto de la tesis doctoral de Juliana Sterli (Sterli, 2009) y 
de estudios ulteriores (Sterli y de la Fuente, 2010; Cerda et al., 2015).

Un párrafo aparte merecen los estudios recientes Ilevados a cabo sobre los Testudinata Meiolaniformes. Los mismos (Gaffney et al., 2007; Sterli y de la Fuente, 2011b, 2013; Sterli et al., 2013, 2015) no solo permitieron constatar una incipiente diversidad del stem Meiolaniidae en el Cretácico de Patagonia (e.g., Chubutemys copelloi, Patagoniaemys patagonica, Trapalcochelys sulcata) sino también explorar las relaciones filogenéticas de estos taxones con el resto de las tortugas y efectuar análisis de biogeografía histórica permitiendo elucidar el origen filogenético y biogeográfico de las tortugas con cornamenta del clado Meiolaniidae (Sterli y de la Fuente, 2013; Sterli, 2015; Sterli et al., 2015) el cual quedó conformado en el territorio argentino por dos especies (Niolamia argentina y Gaffneylania auricularis), del Eoceno Medio de Patagonia (Sterli y de la Fuente, 2011a; Sterli et al., 2015).

Finalmente, durante este último periodo también se realizaron nuevos trabajos de síntesis, algunos de índole más general sobre tetrápodos continentales cretácicos (de la Fuente et al., 2007), reptiles marinos jurásico-cretácicos (Gasparini et al., 2007; Gasparini et al., 2015a) o reptiles presentes en ciertas formaciones (Gasparini et al., 2015b). Otros trabajos más específicos se efectuaron para actualizar el estado del conocimiento de las tortugas mesozoicas de Patagonia (de la Fuente, 2007) o sobre el registro fósil de tortugas de determinadas formaciones (Gasparini y de la Fuente, 2000). En otro estudio se realizó un trabajo de síntesis de todas las especies extintas y actuales del territorio argentino en el marco de una obra de mayor magnitud sobre el origen, la evolución y la historia biogeográfica de las tortugas continentales de Sudamérica (de la Fuente et al., 2014), así como también se presentaron síntesis detalladas de tortugas extintas argentinas en sendas revisiones sobre los Pan-Chelidae de América del Sur y Australasia (Maniel y de la Fuente, en prensa) y sobre los Meiolaniformes de Gondwana (Sterli, 2015).

Hacer mención o incluso escribir un breve resumen de todos y de cada uno de los trabajos publicados en esta última etapa excede el alcance de este estudio, por lo que muchos trabajos no han sido mencionados en este raconto. Sin animosidad, en esta etapa se citaron los trabajos más re- levantes o que mencionan hallazgos importantes a nivel mundial sobre la evolución de las tortugas. Un conteo general de los trabajos sobre tortugas extintas argentinas publicados en esta etapa arroja números mayores a 60 publicaciones. Además, esta etapa actual está caracterizada, no solo por el estudio de materiales presentes en las diferentes colecciones de Argentina, sino también por los numerosos esfuerzos para prospectar y recuperar nuevos especímenes de tortugas extintas a lo largo y ancho del país (Fig. 2). Dichas tareas se han desarrollado en afloramientos de distintas edades, desde el Triásico Tardío (Formación Los Colorados, La Rioja) hasta el Eoceno Medio-Mioceno Medio (Formación Sarmiento, Chubut). El hallazgo de nuevos materiales, sumado a los científicos trabajando en el tema, muestra un buen presente y auguran un futuro promisorio para esta línea de investigación. Los nuevos hallazgos y la aplicación de nuevas metodologías (e.g., paleohistología, morfometría geométrica) permiten, por otro lado, el desarrollo de nuevas sub-líneas de investigación y la diversificación y profundización de los estudios anatómico-descriptivos.

Cabe destacar que en la actualidad la línea de estudio fomentada por la Dra. Zulma Gasparini sobre tortugas extintas cuenta con la participación activa de dos investigadores abocados plenamente al tema (Dres. de la Fuente y Sterli), como así también de investigadores que siguen vinculados al estudio de las tortugas fósiles a pesar de estar abocados a otros temas de investigación (Dras. Bona, Fernández, Gasparini). La influencia de la Dra. Gasparini se ve reflejada en la dirección de las tesis doctorales de $\mathrm{M}$. S. de la Fuente y M. S. Fernández, como así también en la co-dirección de las tesis doctorales de P. Bona y J. Sterli (Fig. 3). Esta línea de investigación se sigue expandiendo en la actualidad, ya que se han estado incorporando nuevos estudiantes. Es así en este momento hay un becario postdoctoral (Dr. Vlachos), tres becarios doctorales (Lics. Jannello, Maniel, Zacarías) y una estudiante de grado (Oriozabala) realizando sus investigaciones en tópicos relacionados con la evolución de tortugas extintas. Como se puede observar, en el periodo actual no sólo hubo un crecimiento en el número de publicaciones, sino también en la formación de recursos humanos que permitan seguir desarrollando, expandiendo y profundizando las investigaciones sobre la evolución de los 


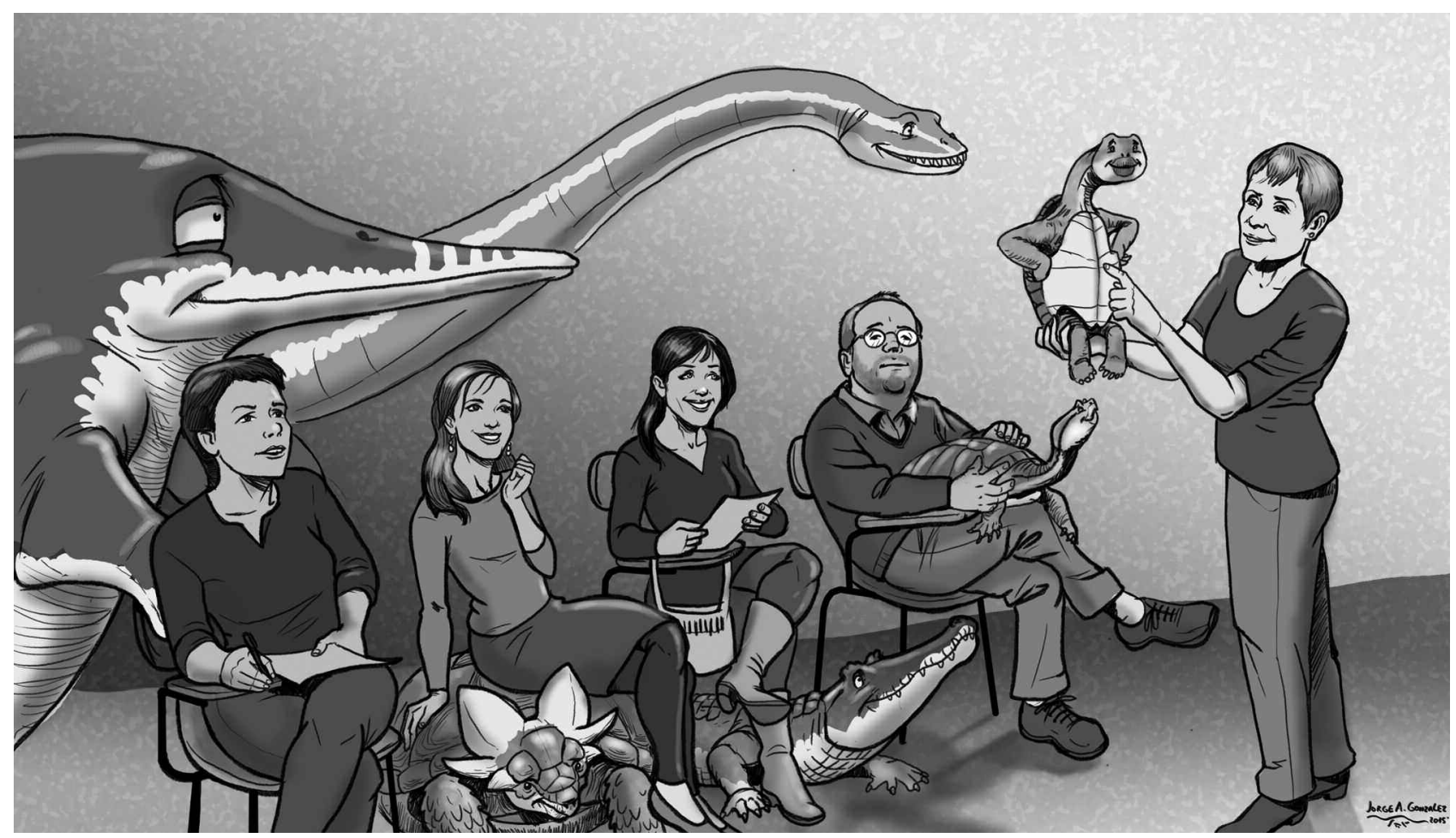

Figura 3. Caricatura en la que se observa a la Prof. Dra. Zulma B. de Gasparini dando directivas generales para el estudio de tortugas a dos generaciones de discípulos: Dra. Marta Fernández y Dr. Marcelo de la Fuente (tesistas siglo XX) y a las Dras. Paula Bona y Juliana Sterli (tesistas siglo XXI).

quelonios en el territorio argentino, contextualizando los haIlazgos en un marco global de evolución del clado. Argentina en la actualidad cuenta con el grupo más grande de investigación sobre el tema a nivel sudamericano y uno de los más grandes a nivel mundial. Todo esto es posible gracias al apoyo brindado por la Dra. Gasparini en los inicios de esta línea de investigación.

\section{CONCLUSIONES}

El estudio de los Testudinata extintos del territorio argentino se ha realizado por más de 150 años desde mediados de siglo XIX hasta la actualidad. Tres etapas bien diferenciadas se reconocen desde ese entonces. La primera etapa, comprendida entre 1858 y 1965, es la más extensa y abarca más de 100 años. Esta etapa se caracterizó por brindar una variedad de estudios, muchos de ellos incipientes, realizados por los naturalistas del siglo XIX, hasta desarrollar estudios más detallados efectuados por los pioneros de la Paleontología de Vertebrados (i.e., George Gaylor Simpson). Durante la misma se publicaron alrededor de 18 contribuciones. Una segunda etapa (1966-1993) se distinguió por un gran número de obras de síntesis desde vertebrados (i.e., trabajos de Rosendo Pascual y colaboradores), pasando por síntesis de anfibios y reptiles (i.e., trabajos de Báez y Gasparini) hasta las más específicas sobre tortugas (e.g., trabajos de France Broin y Marcelo de la Fuente). Nueve trabajos de síntesis y otros nueve trabajos específicos sobre tortugas se publicaron en estos 27 años. Finalmente, en el último período, que se extendió desde 1994 hasta la actualidad, se incrementó tanto el número como la especificidad de los estudios, publicándose alrededor de 64 contribuciones. Se destaca la contribución de la Prof. Dra Zulma B. de Gasparini en el desarrollo de los estudios sobre tortugas fósiles en el país mediante su participación en los trabajos de síntesis desarrollados en la segunda etapa mencionada y en la formación de discípulos que han posibilitado el desarrollo y la continuidad de una línea de investigación sobre la paleoqueloniología en la República Argentina. 


\section{AGRADECIMIENTOS}

Los autores deseamos expresar nuestro agradecimiento a M.S. Fernández e Y. Herrera (MLP) por invitarnos a participar de este volumen especial en homenaje a la Prof. Dra. Zulma B. de Gasparini. A A. Kramarz (MACN) y M. Reguero (MLP) por su buena disposición y facilidades brindadas en diversas oportunidades al revisar las colecciones a su cargo. A E. Tonni, M. Fernández y G. Rougier por las fotos suministradas, a E. Vlachos (MEF) por el diseño de la Figura 1 y a J. González (La Plata) por haber realizado la ilustración de la Figura 3 de esta contribución. Finalmente agradecemos a G. Ottone y a un revisor anónimo por las sugerencias vertidas, las cuales permitieron mejorar el texto del manuscrito original. Este trabajo fue parcialmente financiado por el PICT 2013-0095 (MSdelaF).

\section{REFERENCIAS}

Ambrosetti, J. 1893. Contribución al estudio de las tortugas oligocenas de los terrenos terciarios antiguos del Paraná. Boletín Instituto Geográfico Argentino 14: 489-499.

Ameghino, F. 1882. Catálogo explicativo de las colecciones de antropología prehistórica y de paleontología de Florentino Ameghino. Catálogo de la sección de la Provincia de Buenos Aires en la Exposición Sud Americana Anexo A: 35-42.

Ameghino, F. 1898. Sinopsis geológica-paleontológica de la argentina. Segundo Censo de la República Argentina 1: 112-255.

Ameghino, F. 1899. Sinopsis geológica paleontológica. Suplemento (adiciones y correcciones). Censo Nacional, La Plata: 1-13.

Ameghino, F. 1900. L'age des formations sédimentaires de Patagonie. Anales de la Sociedad Científica Argentina 50: 109-130, 145-165, 209-229.

Ameghino, F. 1906. Les formations sedimentaires du Crétacé Superieur et du Tertiaire de Patagonie, avec un parallele entre leurs faunes mammalogiques et celles de l'ancient continent. Anales del Museo Nacional de Historia Natural de Buenos Aires 15: 1-568.

Argañaraz, B. y Piña, C.I. 2000. Quelonios de la Formación Ituzaingó (Mioceno superior-Plioceno), en Villa Urquiza, Entre Ríos, Argentina. En: F.G. Aceñolaza, y R. Herbst (Eds.), El Neógeno de Argentina. Correlación Geológica 14, INSUGEO, San Miguel de Tucumán, p. 239-244.

Auffenberg, W. 1974. Checklist of fossil land tortoises (Testudinidae). Bulletin of the Florida State Museum, Biological Science 18: 121-246.

Báez, A.M. y Gasparini de, Z.B. 1977. Orígenes y evolución de los anfibios y reptiles del Cenozoico de América del Sur. Acta Geológica Lilloana 14: 149-232.

Báez, A.M. y Gasparini de, Z.B. 1979. The South American Herpetofauna. An evaluation of the fossil record. En: W.E. Duellman (Ed.), The South American Herpetofauna: Its origins, evolution and dispersal. Museum of Natural History, University of Kansas, Monograph 7, p. 29-54.

Bona, P. 2004. [Sistemática y biogeografía de las tortugas y los cocodrilos paleocenos de la Formación Salamanca, Provincia de Chubut, Argentina. Tesis Doctoral, Facultad de Ciencias Naturales y Museo. Universidad Nacional de La Plata, La Plata, Argentina, 159 p. Inédita.].

Bona, P. 2006. Paleocene (Danian) chelid turtles from Patagonia, Argentina: taxonomic and biogeographic implications. Neues Jahrbuch für Geologie und Palaeontologie 241: 303-323.

Bona, P. y de la Fuente, M.S. 2005. Phylogenetic and paleobiogeographic implications of Yaminuechelys maior(Staesche, 1929) new comb. A large long-necked chelid turtle from the Early Paleocene of Patagonia. Journal of Vertebrate Paleontology 25: 569-582.
Bona, P., Cladera, G. y de la Fuente, M.S. 1998. Las tortugas pleurodiras de la Formación Salamanca (Paleoceno inferior) en el área de Cerro Hansen, Provincia de Chubut, Argentina. $10^{\circ} \mathrm{Con}-$ greso Latinoamericano de Geología y $4^{\circ}$ Congreso Nacional de Geología Económica (Buenos Aires), Actas 1: 269-274.

Bona, P., de la Fuente, M.S. y Reguero, M. 2010. New fossil turtle remains from the Eocene of the Antarctic Peninsula. Antarctic Science 22: 531-532.

Bossi, G.E. y Palma, R.M. 1982. Reconsideración de la estratigrafía del Valle de Santa María, Provincia de Catamarca. $5^{\circ}$ Congreso Latinoamericano de Geología (Buenos Aires), Actas 1: 155-172.

Bravard, A. 1858. Monografía de los terrenos marinos terciarios de las cercanías del Paraná. Registro Oficial, Buenos Aires, 107 p.

Broin, F. de. 1987. The Late Cretaceous Fauna of Los Alamitos, Patagonia, Argentina. Part IV, Chelonia. Revista del Museo Argentino de Ciencias Naturales 'Bernardino Rivadavia', Paleontología 3: 131-139.

Broin, F. de. 1991. Fossil turtles form Bolivia. Revista Técnica Yacimientos Petroliferos Fiscales de Bolivia 12: 509-527.

Broin, F. de, y de la Fuente, M.S. 1993a. Les tortues fossiles d'Argentine: première synthèse. Documents des laboratoires de Géologie Lyon 125: 73-84.

Broin, F. de, y de la Fuente, M.S. 1993b. Les tortues fossiles d'Argentine: synthèse. Annales de Paléontologie 79: 169-232.

Burmeister, G. 1885. Examen crítico de los mamíferos y reptiles fósiles denominados por Don Augusto Bravard. Anales del Museo Público de Buenos Aires 3: 95-173.

Cabrera, M. 2014. Orígenes y progreso de la queloniología en Argentina. Cuadernos de Herpetología 28: 11-17.

Cattoi, N. y Freiberg, M. 1958. Una nueva especie de "Podocnemis" del Cretáceo argentino. Physis 21: 58-67.

Cattoi, N. y Freiberg, M. 1961. Nuevo hallazgo de Chelonia extinguidos en la República Argentina. Physis 22: 202.

Cerda, I.A., Sterli, J. y Scheyer, T.M. 2015. Bone shell microstructure of Condorchelys antiqua Sterli, 2008, a stem turtle from the Jurassic of Patagonia. Comptes Rendus Palevol. Doi:10.1016/ j.crpv.2015.01.004.

Cione, A.L., Azpelicueta, M., Bond, M., Carlini, A., Casciotta, R., Cozzuol, M., de la Fuente, M.S., Gasparini, Z., Goin, J., Noriega, J., Scillato-Yané, J., Soibelzon, L., Tonni, E.P., Verzi, D. y Vucetich, M.G. 2000. Miocene vertebrates from Paraná, eastern Argentina. Correlación Geológica 14: 191-237.

Datta, P.M., Manna, P., Ghosh, S.C. y Das, D.P. 2000. The first Jurassic turtle from India. Palaeontology 43: 99-109.

de la Fuente, M.S. 1986. Un quélido Montehermosense (Plioceno temprano-medio) en las proximidades de Cosquín, Provincia de Córdoba, Argentina. Ameghiniana 23: 65-74.

de la Fuente, M.S. 1988. [Las tortugas Chelidae (Pleurodira) y Testudinidae (Cryptodira) del Cenozoico argentino. Tesis Doctoral, Facultad de Ciencias Naturales y Museo, Universidad Nacional de la Plata, La Plata, Argentina, vol. 1: 270 p., vol. 2: 64 pl. Inédita.].

de la Fuente, M.S. 1992. Las tortugas Chelidae del Terciario superior y Cuaternario del territorio argentino. Ameghiniana 29: 211299.

de la Fuente, M.S. 1994. Descripción de nuevos especímenes y relaciones filogenéticas de Chelonoidis gringorum (Chelonii: Testudinidae) del Mioceno temprano de Patagonia central. Stvdia Geologica Salmanticensia 30: 107-131.

de la Fuente, M.S. 1997a. Las tortugas terrestres gigantes del Mioceno tardío-Plioceno del territorio argentino. Stvdia Geologica Salmanticensia 33: 91-120.

de la Fuente, M.S. 1997b. Las tortugas pleistocenas del extremo 
meridional de la provincia de Santa Fé, Argentina. Stvdia Geologica Salmanticensia 33: 67-90.

de la Fuente, M.S. 1999. A review of the Pleistocene Reptiles of Argentina: taxonomic and palaeoenvironmental considerations. En: E.P. Tonni y A.L. Cione (Eds.), Quaternary Vertebrate Paleontology in Southern South America, Quaternary of South America and Antarctic Peninsula, Special Volume 12, A. A. Balkema, Rotterdam, p. 111-138.

de la Fuente, M.S. 2003. Two new Pleurodiran turtles from Portezuelo Formation (Upper Cretaceous) of northern Patagonia, Argentina. Journal of Paleontology 77: 559-575.

de la Fuente, M.S. 2007. Testudines. En: Z. Gasparini, R. Coria y L. Salgado (Eds.), Patagonian Mesozoic Reptiles. Indiana University Press, Bloomington, p. 50-86.

de la Fuente, M. y Bona, P. 2002. Una nueva especie de Hydromedusa Wagler, 1830 (Pleurodira, Chelidae) del Paleógeno de Patagonia. Ameghiniana 39: 77-83.

de la Fuente, M.S. y Cabrera, M. 1988. Comentarios sobre las tortugas fósiles de Sierra Chica (provincia de Córdoba, Argentina). Boletin de la Asociación Herpetológica Argentina 4: 65-74.

de la Fuente, M.S. y Casadío, S. 2000. Un nuevo osteopigino (CheIonii: Cryptodira) de la Formación Roca (Paleoceno Inferior) de Cerros Bayos, Provincia de La Pampa, Argentina. Ameghiniana 37: 235-246.

de la Fuente, M.S. y Fernández, M.S. 1989. Notoemys laticentralis Cattoi \& Freiberg, 1961 from the Upper Jurassic of Argentina: a member of the infraorder Pleurodira (1868). Stvdia Palaeocheloniologica 3: 25-32.

de la Fuente, M.S. y Fernández, M. 1992. Un nuevo resto de MeioIaniidae (Chelonii: Cryptodira) del Terciario temprano de Patagonia. Acta Zoologica Lilloana 41: 365-369.

de la Fuente, M.S. y Fernández, M.S. 2011. An unusual pattern in the limb morphology of the Tithonian marine turtle Neusticemys neuquina from the Vaca Muerta Formation (Neuquén Basin) Argentina. Lethaia 44: 15-25.

de la Fuente, M.S. y de Lapparent de Broin, F. 1997. An Araripemyslike decorated pleurodire turtle in the Paleocene of northwestern Argentina. Geobios 30: 235-242.

de la Fuente, M.S. y Vucetich, M.G. 1998. Nuevos materiales de tortugas cryptodiras miocenas del Valle del Chubut. Ameghiniana 35: 211-215.

de la Fuente, M.S., Barbieri, R. y Chafrat, P. 2010. Una tortuga Chelidae (Testudines: Pleurodira) de cuello largo en el Grupo Neuquén, Río Negro, Argentina. Significado cronológico y paleobiogeográfico. Andean Geology 37: 399-413.

de la Fuente, M.S., Calvo, J. y González Riga, B.J. 2007. A new Cretaceous chelid turtle from Northern Neuquén Basin, Neuquén Province, Argentina. Ameghiniana 44: 485-492.

de la Fuente, M.S., Lapparent de Broin, F. de, y Manera de Bianco, T. 2001. The oldest and first nearly complete skeleton of a chelid, of the Hydromedusa group (Chelidae, Pleurodira), from the Upper Cretaceous of Patagonia. Bulletin de la Société Geologique de France 172: 237-244.

de la Fuente, M.S., Noriega, J.I. y Piña, C.I. 2002. Trachemys dorbigni (Duméril y Bibron, 1835) (Cryptodira: Emydidae) en el Pleistoceno tardío de la provincia de Entre Ríos, Argentina. Cuadernos de Herpetología 16: 65-72.

de la Fuente, M.S., Santillana, S.N. y Marenssi, S. 1995. An Eocene leatherback turtle (Cryptodira: Dermochelyidae) from Seymour Island, Antarctica. Stvdia Geologica Salmanticensia 31: 17-30.

de la Fuente, M., Sterli, J. y Maniel, I. 2014. Origin, Evolution and Biogeographic History of South American Turtles. Springer Earth Sys- tem Sciences, Dordrecht and Heidelberg, $168 \mathrm{p}$.

de la Fuente, M.S., Ciccioli, P., Limarino, O., Gutiérrez, P. y Fauque, L. 2003. Quelonios podocnemídidos en la Formación Puesto La Flecha (Oligoceno), Precordillera de la Rioja, Argentina. Ameghiniana 40: 617-624.

de la Fuente, M.S., Fernández, M.S., Parras, A. y Herrera, Y. 2009. Euclastes meridionalis (de la Fuente \& Casadío) from Danian levels of the Jagüel Formation at Cerro Azul, Northern Patagonia, Argentina. Neues Jahrbuch für Geologie und Paläontologie Abhandlungen 253: 327-339.

de la Fuente, M.S., Umazano, A.M., Sterli, J. y Carballido, J.I. 2011. New chelid of the lower section of the Cerro Barcino formation (Aptian-Albian?), Patagonia. Cretaceous Research 32: 527-537.

de la Fuente, M.S., Novas, F., Isasi, M., Lirio, J.M. y Nuñez, H. 2010. First Cretaceous turtle from Antarctica. Journal of Vertebrate Paleontology 30: 1275-1278.

de la Fuente, M.S., Maniel, I., Jannello, J.M., Filippi, L. y Cerda, I. 2015. Long-necked chelid turtles from the Campanian of northwestern Patagonia with comments on K/P survivorship of the genus Yaminuechelys. Comptes Rendus Palevol 14: 563-576.

de la Fuente, M.S., Salgado, L., Albino, A., Báez, A.M., Bonaparte, J.F., Calvo, J.O., Chiappe, L.M., Codorniú, L.S., Coria, R., Gasparini, Z., González Riga, B.J, Novas, F.E. y Pol, D. 2007. Tetrápodos continentales del Cretácico de la Argentina: una síntesis actualizada. Publicación Especial de la Asociación Paleontológica Argentina 11: 137-153.

Estes, R. y Báez, A.M. 1985. Herpetofaunas of North and South America during the Late Cretaceous and Cenozoic: evidence for interchange? En: F. Stahli y D. Webb (Eds.), The great American biotic interchange. Topics in Geobiology 4. Plenum Press, New York, p. 140-197.

Fernández, M.S. y de la Fuente, M.S. 1993. Las tortugas casiquélidias de las calizas litográficas titonianas del área Los Catutos Argentina. Ameghiniana 30: 283-295.

Fernández, M.S. y de la Fuente, M.S. 1994. Redescription and phylogenetic position of Notoemys the oldest gondwanian pleurodiran turtle. Neues Jahrbuch für Geologie und Paläontologie Abhandlungen 193: 81-103.

Gaffney, E.S., Hutchison, J.H., Jenkins, F.A. y Meeker, L.J. 1987. Modern turtle origins: the oldest known cryptodire. Science 237: 289-292.

Gaffney, E.S., Rich, T.H., Vickers-Rich, P., Constantine, A., Vacca, R. y Kool, L. 2007. Chubutemys, a new eucryptodiran turtle from the Early Cretaceous of Argentina, and the relationships of the Meiolaniidae. American Museum Novitates 3599: 1-35.

Gasparini, Z. y Báez, A.M. 1975. Aportes al conocimiento de la Herpetofauna Terciaria de la Argentina. $1^{\circ}$ Congreso Argentino de Paleontología y Bioestratigrafía (San Miguel de Tucumán), Actas 2: 377-416.

Gasparini, Z. y de la Fuente, M.S. 2000. Tortugas y plesiosaurios de la Formación La Colonia (Cretácico superior) de Patagonia, Argentina. Revista Española de Paleontología 15: 23-36.

Gasparini, Z., de la Fuente, M.S., y Donadío, O. 1986. Los reptiles cenozoicos de la Argentina. $4^{\circ}$ Congreso Argentino de Paleontología y Bioestratigrafía (Mendoza), Actas 2: 119-130.

Gasparini, Z., Spalletti, L. y de la Fuente, M.S. 1997. Marine reptiles of a Tithonian transgression, Western Neuquén Basin, Argentina. Facies and Palaeonvironments. Geobios 30: 701-712.

Gasparini, Z., Fernández, M., de la Fuente, M.S. y Salgado, L. 2007. Reptiles marinos jurásicos y cretácicos de la Patagonia argentina: su aporte al conocimiento de la herpetofauna mesozoica. Publicación Especial de la Asociación Paleontológica 
Argentina 11: 125-136.

Gasparini, Z., Spalletti, L., Fernández, M. y de la Fuente, M.S. 1999. Tithonian marine reptiles from the Neuquén Basin: Diversity and paleonvironments. Revue de Paléobiologie 18: 335-345.

Gasparini, Z., Fernández, M., de la Fuente, M.S., Herrera, Y., Codorniú, L. y Garrido, A. 2015a. Reptiles from Lithographic limestones of the Los Catutos Member (Middle-Upper Tithonian), Neuquén Province, Argentina: An essay on its taxonomic composition and preservation in an environmental and geographic context. Ameghiniana 52: 1-28.

Gasparini, Z., Sterli, J., Parras, A., O'Gorman, J.P., Salgado, L., Varela, J. y Pol, D. 2015b. Late Cretaceous reptilian biota of the La Colonia Formation, central Patagonia, Argentina: Occurrences, preservation and paleoenvironments. Cretaceous Research 54: 154-168.

Gayet, M., Marshall, L. y Sampere, T. 1991. The Mesozoic and Paleocene vertebrates of Bolivia and their stratigraphic context: a Review. Revista Técnica Yacimientos Petrolíferos Fiscales de Bolivia 12: 393-433.

Hay, O.P. 1908. The Fossil Turtles of North America. Carnegie Institution Washington Publications 75: 1-568.

Joyce, W.G. y Faux, C. 2008. "Chelys patagonica" from the Pliocene of Argentina: not lost, not valid, not a chelid turtle. Ameghiniana 45: 801-803.

Joyce, W.G., Parham, J.F. y Gauthier, J.A. 2004. Developing a protocol for the conversion of rank-based taxon names to phylogenetically defined clade names, as exemplified by turtles. Journal of Paleontology 78: 989-1013.

Khun, O. 1964. Fossilium Catalogus, Volume 1, Animalia, Part 107, Testudines. Gravenhage, Ysel Press, 299 p.

Lapparent de Broin, F. de, y de la Fuente, M. 2001. Oldest world Chelidae (Chelonii, Pleurodira), from the Cretaceous of Patagonia. Comptes Rendus Académie des Sciences de Paris 333: 463470.

Lapparent de Broin, F. de, de la Fuente, M.S. y Fernández, M.S. 2007. Notoemys (Chelonii, Pleurodira), Late Jurassic of Argentina: new examination of the anatomical structures and comparisons. Revue de Paléobiologie 26: 99-136.

Maniel, I. 2011. [Diversidad y paleoambiente de las tortugas de la localidad La Bonita (Sub-Grupo Rio Colorado, Grupo Neuquén), Cretácico de Patagonia. Disertación de Tesis de Licenciatura, Facultad de Ciencias Exactas y Naturales, Universidad de Buenos Aires, Buenos Aires, 93 p. Inédita.].

Maniel, I. y de la Fuente, M.S. En prensa. A review of the fossil record of turtles of the Clade Pan-Chelidae. Bulletin of the Peabody Museum of Natural History Yale University.

Manzano, A., Noriega, J.I. y Joyce, W. 2009. The tropical tortoise Chelonoidis denticulata (Testudines: Testudinidae) from the late Pleistocene of Argentina and its paleoclimatological implications. Journal of Paleontology 83: 975-980.

Marshall, L. y Patterson, B. 1981. Geology and geochronology of the mammal-bearing Tertiary of the Valle de Santa María and Río Corral Quemado, Catamarca province, Argentina. Fieldiana Geology 9: 1-80.

Marshall, L., Hoffstetter, R. y Pascual, R. 1983. Mammals and Stratigraphy: Geochronology of the continental mammalbearing Tertiary of South America. Palaeovertebrata Mémoire Extraordinaire 1983: 1-93.

Moreno, F.P. 1889. Breve reseña de los progresos del Museo de La Plata durante el Segundo semestre de 1888. Boletín Museo de La Plata 2: 1-44.

Noriega, J., Manzano, A., de la Fuente, M. y Tonni, E. 2000. Un Tes- tudininae gigante (chelonii: Cryptodira) del Pleistoceno de la Provincia de Corrientes, Argentina. Ameghiniana 37: 321-326.

Parham, J.F. y Pyenson, N.D. 2010. New sea turtle from the Miocene of Peru and the iterative evolution of feeding ecomorphologies since the Cretaceous. Journal of Paleontology 84: 231-247.

Pascual, R. 1966. En: A.V. Borrello (Ed.) Paleontografía Bonaerense. Fascículo 4 (Vertebrados). Comisión de Investigaciones Científicas, La Plata, 202 p.

Pascual, R. y Odreman Rivas, O. 1971. Evolución de las Comunidades de los Vertebrados del Terciario de Argentina. Los aspectos Paleozoogeográficos y Paleoclimáticos relacionados. Ameghiniana 8: 372-412.

Pascual, R., Bond, M. y Vucetich, M.G. 1981. El subgrupo Santa Bárbara (Grupo Salta) y sus vertebrados, cronología, paleoambientes y paleobiogeografía. $8^{\circ}$ Congreso Geológico Argentino (San Luis), Actas 3: 743-758.

Riggs, E. y Patterson, B. 1939.Stratigraphy of the Late Miocene and Pliocene deposits of the province of Catamarca (Argentina) with notes on the fauna. Physis 14: 143-162.

Rhodin, A.G.J., Thomson, S., Georgalis, G., Karl, H.-V., Danilov, I.G., Takahashi, A., de la Fuente, M.S., Bourque, J.R., Delfino, M., Bour, R., Iverson, J.B., Shaffer, H.B. y van Dijk, P.P. 2015. Turtles and tortoises of the world during the rise and global spread of humanity: first checklist of extinct Pleistocene and Holocene chelonians. En: A.G.J. Rhodin, P.C.H. Pritchard, P.P. van Dijk, R.A. Saumure, K.A. Buhlmann, J.B. Iverson y R.A. Mittermeier (Eds). Conservation Biology of Freshwater Turtles and Tortoises: A Compilation Project of the IUCN/SSC Tortoise and Freshwater Turtle Specialist Group. Chelonian Research Monographs 5, Chelonian Research Foundation, Lunenburg, p. 1-66.

Rougier, G., de la Fuente, M.S. y Arcucci, A. 1995. Late Triassic turtles from South America. Science 268: 855-858.

Rougier, C., de la Fuente, M.S. y Arcucci, A. 1998. La evolución de las tortugas. Investigación y Ciencia 258: 62-70.

Rovereto, C. 1914. Los Estratos Araucanos y sus Fósiles. Anales Museo Nacional de Historia Natural de Buenos Aires 25: 1-249.

Rusconi, C. 1934. Tercera noticia sobre los vertebrados fósiles de la arenas puelchenses de Villa Ballester. Anales de la Sociedad Cientifica Argentina 117: 19-37.

Santa Cruz, J.N. 1972. Estudio sedimentológico de la Formación Puelches en la provincia de Buenos Aires. Revista de la Asociación Geológica Argentina 27: 5-62.

Scalabrini, P. 1884. Conferencia dada el 6 de Enero en la Sección del Paraná. Boletín Instituto Geográfico Argentino 5: 15-19.

Scalabrini, P. 1887. Cartas Científicas Museo de la Provincia de Entre Ríos. Tipografía y Encuadernación La Velocidad, Paraná, 209 p.

Scanferla, A., Agnolín, A., Novas, F.E., de la Fuente, M.S., Bellosi, E., Báez, A.M. y Cione, A. 2011. A vertebrate assemblage of Las Curtiembres Formation (Upper Cretaceous) of northwestern Argentina. Revista del Museo Argentino de Ciencias Naturales 13: $195-202$.

Simpson, G.G. 1938. Crossochelys, Eocene horned turtle from Patagonia. Bulletin American Museum of the Natural History 74: 221-254.

Simpson, G.G. 1942. A Miocene tortoise from Patagonia. American Museum Novitates 1209: 1-6.

Simpson, G.G. 1943. Turtles and the origin of the fauna of Latin America. American Journal of Sciences 241: 413-429.

Staesche, K. 1929. Schildkrötenreste aus der oberen Kreide Patagoniens. Paläeontographica 72: 103-112.

Sterli, J. 2008. A new, nearly complete stem turtle from the Juras- 
sic of South America with implications for turtle evolution. Biology Letters 4: 286-289.

Sterli, J. 2009. [Sistemática y paleobiogeografía de las tortugas continentales del Jurásico de Patagonia, Argentina. Tesis Doctoral, Facultad de Ciencias Naturales y Museo, Universidad Nacional de La Plata, La Plata, 530 p. Inédita.].

Sterli, J. 2015. A review of the fossil record of the Gondwanan turtles of the clade Meiolaniformes. Bulletin of the Peabody Museum of Natural History Yale University 56: 21-45.

Sterli, J. y de la Fuente, M. 2010. Anatomy of Condorchelys antiqua Sterli, 2008 and the origin of the modern jaw closure mechanism in turtles. Journal of Vertebrate Paleontology 30: 351-366.

Sterli, J. y de la Fuente, M.S. 2011a. Re-description and evolutionary remarks on the Patagonian horned turtle Niolamia argentina Ameghino, 1989 (Testudinata: Meiolaniidae). Journal of Vertebrate Paleontology 31: 1210-1229.

Sterli, J. y de la Fuente, M.S. 2011b. A new turtle from the La Colonia Formation (Campanian-Maastrichtian), Patagonia, Argentina, with remarks on the evolution of the vertebral column in turtles. Palaeontology 54: 63-78.

Sterli, J. y de la Fuente, M.S. 2013. New evidence from the Paleocene of Patagonia (Argentina) on the evolution and paleobiogeography of meiolaniform turtles (Testudinata, new taxon name). Journal of Systematic Palaeontology 11: 835-852.

Sterli, J. y Joyce, W.G. 2007. The cranial anatomy of the lower Jurassic turtle Kayentachelys aprix. Acta Palaaeontologica Polonica 52: 675-694.

Sterli, J., de la Fuente, M.S. y Cerda, I. 2013. A new species of Meiolaniform turtle and revision of the Late Cretaceous Meiolaniformes of South America. Ameghiniana 50: 240-256.

Sterli, J., de la Fuente, M.S. y Krause, M. 2015. A new turtle from the Palaeogene of Patagonia (Argentina) shed new light on the diversity and evolution of the bizarre clade of horned turtles (Meiolaniidae, Testudinata). Zoological Journal of the Linnean Society 174: 519-548.

Sterli, J., de la Fuente, M.S. y Rougier, G. 2007. Anatomy and relationships of Palaeochersis talampayensis, a Late Triassic turtle from Argentina. Palaeontographica Abteilung A 281: 1-61.

Wieland, G. 1923. A new Parana Pleurodiram. American Journal of Sciences 5: 1-14.
Williams, E.E. 1950. Variation and selection in the cervical central articulations of living turtles. Bulletin of the American Museum of Natural History 94: 511-561.

Wood, R.C. y Patterson, B. 1973. A fossil trionychid turtle from South America. Breviora 405: 1-10.

Wood, R.C. y Freiberg, M.A. 1977. Redescription of Notoemys laticentralis, the oldest fossil turtle from South America. Acta Geologica Lilloana 13: 187-204.

Woodward, A.S. 1901. On some extint reptiles from Patagonia of the genera Miolania, Dinilysia and Genyodectes. Proceedings of the Zoological Society, London 1901: 169-184.

Zacarías, G.G. 2012. [Tortugas terrestres (Testudinidae) gigantes del Pleistoceno de la Provincia de Corrientes, Argentina, Anatomía y Sistemática. Tesis de Licenciatura Facultad de Ciencias Exactas, Naturales y Agrimensura, Universidad Nacional del Nordeste, Corrientes, 48 p. Inédita.].

Zacarías, G., de la Fuente, M.S. y Zurita, A. 2014. Testudinoidea Fitzinger (Testudines: Cryptodira) de la Formación Toropí-Yupoí (CA. 58-28 ka) en la provincia de Corrientes, Argentina: Taxonomía y aspectos paleoambientales relacionados. Revista Brasileira de Paleontología 17: 389-404.

Zacarías, G.G., de la Fuente, M.S., Fernández, M.S. y Zurita, A.E. 2013. Nueva especie de tortuga terrestre gigante del género Chelonoidis Fitzinger 1835 (Cryptodira: Testudinidae), del miembro inferior de la Formación Toropí/Yupoi (Pleistoceno Tardío/Lujanense), Bella Vista, Corrientes, Argentina. Ameghiniana 50: 298-318.

Recibido: 17 de agosto de 2015

Aceptado: 28 de septiembre de 2015 